\title{
Information Technology and Productivity: Where Are We Now and Where Are We Going?*
}

\author{
Stephen D. Oliner \\ Federal Reserve Board
}

\author{
Daniel E. Sichel \\ Federal Reserve Board
}

May 10, 2002

\footnotetext{
* We would like to thank Darrel Cohen, John Fernald, Jaime Marquez, and David Stockton for very useful comments and discussions, as well as participants at the Atlanta Federal Reserve Bank's January 2002 conference on Technology, Growth, and the Labor Market. For extremely valuable help with data, we are grateful to Charlie Gilbert from the Federal Reserve Board, Bruce Grimm and David Wasshausen from the Bureau of Economic Analysis, and Michael Harper, Larry Rosenblum, and Steve Rosenthal from the Bureau of Labor Statistics. The views expressed in this paper are those of the authors and should not be attributed to the Board of Governors of the Federal Reserve System or its staff.
} 


\begin{abstract}
Productivity growth in the U.S. economy jumped during the second half of the 1990s, a resurgence that many analysts linked to information technology (IT). However, shortly after this consensus emerged, demand for IT products fell sharply, leading to a lively debate about the connection between IT and productivity and about the sustainability of the faster growth. We contribute to this debate in two ways. First, to assess the robustness of the earlier evidence, we extend the growth-accounting results in Oliner and Sichel (2000a) through 2001. The new results confirm the basic story in our earlier work - that the acceleration in labor productivity after 1995 was driven largely by the greater use of IT capital goods and by the more rapid efficiency gains in the production of IT goods. Second, to assess whether the pickup in productivity growth is sustainable, we analyze the steady-state properties of a multi-sector growth model. This exercise generates a range for labor productivity growth of 2 percent to 2-3/4 percent per year, which suggests that much - and possibly all - of the resurgence is sustainable.
\end{abstract}




\section{INTRODUCTION" $\rrbracket$}

After a quarter century of lackluster gains, the U.S. economy experienced a remarkable resurgence in productivity growth during the second half of the 1990s. From 1995 to 2000, output per hour in nonfarm business grew at an average annual rate of about $2-1 / 2$ percent, compared with increases of only about $1-1 / 2$ percent per year from 1973 to 1995 . Our earlier work, along with other research, linked this improved performance to the information technology (IT) revolution that has spread through the U.S. economy. Indeed, by 2000 , this emphasis on the role of IT had become the consensus view.

However, shortly after this consensus emerged, the technology sector of the economy went into a tailspin as demand for IT products fell sharply. Reflecting this retrenchment, stock prices for many technology firms collapsed, and financing for this sector dried up. These developments raised questions about the robustness of the earlier results that emphasized the role of information technology. They also cast some doubt on the sustainability of the rapid productivity growth in the second half of the 1990s. Nonetheless, the latest data remain encouraging. Productivity gains have continued to be strong, with output per hour rising 2 percent over the four quarters of 2001 - a much larger increase than is typical during a recession.

Against the backdrop of these developments, much effort has been devoted to estimating the underlying trend in productivity growth [see, in particular, Baily (2002), DeLong (2002), Gordon (2002), Jorgenson, Ho, and Stiroh (2002), Kiley (2001), Martin

\footnotetext{
${ }^{1}$ This paper draws heavily from our earlier work, including text taken directly from Oliner and Sichel (2000a and 2000b) and Sichel (1997).

${ }^{2}$ See Oliner and Sichel (2000), Bosworth and Triplett (2000), Brynjolfsson and Hitt (2000), Jorgenson and Stiroh (2000), Jorgenson (2001), and Whelan (2000). For more skeptical views of the role of information technology written at that time, see Gordon (2000).
} 
(2001), McKinsey Global Institute (2001), and Roberts (2001)]. For the most part, these papers take a relatively optimistic view of the long-run prospects for productivity growth. We add to this literature in two ways. First, to assess the robustness of the earlier evidence on the role of IT, we extend the growth-accounting results in Oliner and Sichel (2000a) through 2001. These results continue to support the basic story in our earlier work; namely, the data still show a substantial pickup in labor productivity growth and indicate that both the use of IT and efficiency gains associated with the production of IT were central factors in that resurgence.

Second, to assess whether the pickup in productivity growth since the mid-1990s is sustainable, we analyze the steady-state properties of a multi-sector growth model. This exercise allows us to translate alternative views about the evolution of the technology sector (and other sectors of the economy) into "structured guesses" about future growth in labor productivity. As highlighted by Jorgenson (2001), the pace of technological progress in high-tech industries - especially semiconductors - likely will be a key driver of productivity growth going forward. Thus, we develop a model that is rich enough to trace out the aggregate effects of these driving influences. We view this steady-state machinery not as a forecasting model per se, but rather as a tool for generating a likely range of outcomes for labor productivity growth over roughly the next decade. Beyond that horizon, the uncertainty about the structure and evolution of the economy is too great for our steady-state approach to offer much insight.

Our structured guesses of labor productivity growth range from 2 percent to roughly $2-3 / 4$ percent per year. The lower end of the range reflects conservative assumptions for key parameters in our model. Notably, in this scenario, we assume that 
the rate of technological advance in the semiconductor industry drops back to its historical average from the extremely fast pace in the second half of the 1990s and that the semiconductor and other IT sectors fail to grow any further as a share of (currentdollar) economic activity. In contrast, to generate the upper end of the range, we assume that the pace of technological advance in the semiconductor sector reverts only halfway back to its historical average and that the various IT sectors continue to grow as a share of the economy. Of course, much uncertainty attends this exercise, and we also discuss more extreme scenarios in which labor productivity growth in the steady state would fall short of 2 percent or would exceed 3 percent. We believe, however, that these more extreme alternatives are less likely than the scenarios generating labor productivity growth in the 2 to $2-3 / 4$ percent range. This range, which includes the pace recorded over the second half of the 1990s, puts us squarely in the camp of those who believe that a significant portion - and possibly all - of the mid-1990s productivity resurgence is sustainable.

The next section of the paper provides a largely non-technical overview of our analytical framework. Section 3 briefly discusses the data that we use, while section 4 describes the growth-accounting results extended through 2001. Section 5 lays out the alternative steady-state scenarios that we analyze and then presents the steady-state results. Section 6 concludes. The paper also includes two appendices. Appendix 1 fully describes our multi-sector model and derives all the theoretical results that underlie our growth-accounting and steady-state estimates. Appendix 2 provides detailed documentation for each data series used in the paper. 


\section{ANALYTICAL FRAMEWORK}

This paper employs the neoclassical growth-accounting framework pioneered by Solow (1957) and used extensively by researchers ever since. ${ }^{\text {日 }}$ The neoclassical framework decomposes the growth in labor productivity, measured by output per hour worked, into the contributions from three broad factors: Increases in the amount of capital per hour worked (usually referred to as "capital deepening"), improvements in the quality of labor, and growth in "multifactor productivity" (MFP). MFP is the residual in this framework, capturing improvements in the way that firms use their capital and labor, but also embedding any errors in the estimated contributions from capital deepening and labor quality.

The growth-accounting framework can be tailored to address many different issues. We employ it to assess the growth contribution from IT capital, taking account of both the use of this capital throughout the economy and the efficiency gains realized in its production. Given this focus, we construct a model of the nonfarm business economy that highlights key IT-producing industries. Our model, which extends the two-sector models developed in Martin (2001) and Whelan (2001), divides nonfarm business into five sectors. Four sectors produce final output: Computer hardware, software, communication equipment, and a large non-IT sector that produces all other final goods and services. The fifth sector in the model produces semiconductors, which are either consumed as an intermediate input by the final-output sectors or exported to foreign firms. To focus on the role of semiconductors in the economy, the model abstracts from all other intermediate inputs.

\footnotetext{
${ }^{3}$ See Steindel and Stiroh (2001) for an overview of growth accounting, issues related to the measurement of productivity, and trends in productivity growth in the post-war period.
} 
Our model relies on several assumptions that are typically imposed in growthaccounting studies. In particular, we assume that all markets are perfectly competitive and that production in every sector is characterized by constant returns to scale. Labor and capital are assumed to be completely mobile, which implies a single wage rate for labor across all sectors and a single rental rate for each type of capital. Within this competitive market structure, we assume that firms set their investment and hiring decisions to maximize profits. Moreover, when firms purchase new capital or hire additional workers, we assume they do not incur any "adjustment costs" that would reduce output while these new inputs are integrated into the firms' production routines. Finally, we do not explicitly model cyclical changes in the intensity with which firms use their capital and labor.

These assumptions yield a tractable analytical framework by abstracting from some notable features of the actual economy. One could be concerned that these assumptions are so restrictive as to distort the empirical results. Reflecting such concerns, we would not advocate using a framework such as ours to decompose year-toyear changes in productivity growth, as cyclical factors omitted from the model could substantially affect the results. However, Basu, Fernald, and Shapiro (2001) showed that the basic characterization of productivity trends in the 1990s remains intact even after allowing for adjustment costs, non-constant returns to scale, and cyclical variations in the use of capital and labor.

With this background, we now discuss the key analytical results from our model. The rest of this section presents and interprets these results; formal derivations can be found in appendix 1. 


\section{Growth in Aggregate Labor Productivity}

As shown in the first proposition of appendix 1, our model yields a standard decomposition of growth in aggregate labor productivity. Let $\dot{Z}$ denote the growth rate of any variable $Z$. Then, the growth of output per hour for nonfarm business as a whole can be written as:

$$
\begin{aligned}
\dot{Y}-\dot{H} & =\alpha_{C}^{K}\left(\dot{K}_{C}-\dot{H}\right)+\alpha_{S W}^{K}\left(\dot{K}_{S W}-\dot{H}\right)+\alpha_{M}^{K}\left(\dot{K}_{M}-\dot{H}\right)+\alpha_{O}^{K}\left(\dot{K}_{O}-\dot{H}\right) \\
& +\alpha^{L} \dot{q}+\dot{M F P}, \\
& =\sum_{j=1}^{4} \alpha_{j}^{K}\left(\dot{K}_{j}-\dot{H}\right)+\alpha^{L} \dot{q}+\dot{M F P},
\end{aligned}
$$

where $Y$ denotes nonfarm business output in real terms; $H$ denotes hours worked in nonfarm business; $K_{C}, K_{S W}, K_{M}$, and $K_{O}$ denote the services provided by the stocks of computer hardware, software, communication equipment, and all other tangible capital, respectively; and $q$ denotes labor quality. The $\alpha$ terms are income shares; under the assumptions of our model, the income share for each input equals its output elasticity, and the shares sum to one. The second line of equation 1 merely rewrites the decomposition with more compact notation, where $j$ indexes the four types of capital.

Equation 1 shows that growth in labor productivity reflects capital deepening, improvements in labor quality, and gains in MFP, with the overall growth contribution from capital deepening constructed as the sum of the contributions from the four types of capital. Each such contribution equals the increase in that type of capital per work hour,

\footnotetext{
${ }^{4}$ Time subscripts on both the income shares and the various growth rates have been suppressed to simplify the notation. We use log differences to measure growth rates. The income share applied to a log difference between periods $t$ and $t+1$ is measured as the average of the shares in these two periods.
} 
weighted by the income share for that capital. This decomposition is entirely standard and matches the one used in Oliner and Sichel (2000a and 2000b). Note that equation 1 does not identify the sectors using capital and labor; all that matters is the aggregate amount of each input. Under our assumptions, we need not keep track of the individual sectors because each type of capital has the same marginal revenue product regardless of where it is employed, and the same holds for labor. Hence, transferring capital or labor from one sector to another has no effect on labor productivity for nonfarm business as a whole.

Our growth-accounting decomposition depends importantly on the income shares of the various types of capital. These income shares are not directly observable, and we estimate them in accord with the method used by the Bureau of Labor Statistics. In this framework, the income share for capital of type $j$ is

$$
\alpha_{j}=\left(R+\delta_{j}-\Pi_{j}\right) T_{j} p_{j} K_{j} / p Y,
$$

where $R$ is a measure of the nominal net rate of return on capital, which is the same for all types of capital under our assumption of profit maximization; $\delta_{j}$ is the depreciation rate for capital of type $j ; \Pi_{j}$ measures any expected change in the value of this capital over and above that captured in the depreciation rate; $T_{j}$ is a composite tax parameter; $p_{j} K_{j}$ is the current-dollar stock of this capital; and $p Y$ is total current-dollar income in the nonfarm business sector. The intuition behind equation 2 is straightforward. In a competitive market, each dollar of type $j$ capital must earn a gross annual return that covers the net return common to all capital as well as the loss of value that this capital suffers over the year and the taxes imposed on the income it generates. The product of this gross return and the current-dollar stock equals the current-dollar income assumed to 
be earned by type $j$ capital, which we divide by total income in nonfarm business to obtain the desired income share. Once we calculate each capital share in this way, the labor share is simply one minus the sum of the capital shares.

\section{Aggregate and Sectoral MFP Growth}

The term for aggregate MFP growth in equation 1 can be decomposed into the contributions from MFP growth in each sector. In particular, proposition 1 in the model appendix shows that

$$
\dot{M F P}=\sum_{i=1}^{4} \mu_{i} \dot{M F P_{i}}+\mu_{S} \dot{M F P},
$$

where $i$ indexes the four final-output sectors, $s$ denotes the semiconductor sector, and the $\mu$ term for each sector represents its output expressed as a share of total nonfarm business output, in current dollars. This is the sectoral weighting scheme initially proposed by Domar (1961) and formally justified by Hulten (1978). The "Domar" weights sum to more than one, which may seem odd at first glance. ${ }^{\text {B }}$ However, this weighting scheme is needed to account for the production of intermediate inputs.

Without this "gross-up" of the weights, the MFP gains achieved in producing semiconductors (the only intermediate input in our model) would be omitted from the decomposition of aggregate MFP growth.

To see this point more clearly, note that equation 3 can be rewritten as

$$
\dot{M F P}=\sum_{i=1}^{4} \mu_{i}\left[\dot{M F P_{i}}+\beta_{i}^{S}(1+\theta) \dot{M F P_{S}}\right]
$$

\footnotetext{
${ }^{5}$ It is easy to see that the weights sum to more than one if semiconductor producers sell all of their output to the four final-output sectors, with none sold as exports. In this case, semiconductors are strictly an intermediate input, and production by the four final-output sectors accounts for all nonfarm business output. Hence, the $\mu$ terms for these sectors sum to one before adding in $\mu_{S}$. With a little algebra, one can show that the $\mu$ terms also sum to more than one in the more general case that allows for exports of semiconductors.
} 
where $1+\theta$ equals the ratio of domestic semiconductor output to domestic use of semiconductors and $\beta_{i}^{S}$ denotes semiconductor purchases by final-output sector $i$ as a share of the sector's total input costs. This result, derived in proposition 2 , shows that the semiconductor sector, in effect, can be vertically integrated with the final-output sectors that it supplies. MFP growth in each vertically-integrated sector - the term in brackets subsumes the MFP gains at its dedicated semiconductor plants. Thus, equation 4 shows that the Domar weighting scheme (in equation 3) can be viewed as aggregating MFP growth from these vertically integrated sectors.

To make use of equation 3, we need to estimate MFP growth in each sector of our model. We do this with the so-called "dual" method employed by Triplett (1996) and Whelan (2000), among others. This method uses data on the prices of output and inputs, rather than their quantities, to calculate sectoral MFP growth. We opt for the dual approach because the required data are more readily available.

The basic intuition behind the dual approach can be explained with an example involving semiconductors, the prices of which have trended down sharply over time. To keep the example simple, assume that input prices for the semiconductor sector have been stable. Given the steep decline in semiconductor prices relative to the prices for other goods and services, MFP growth at semiconductor producers must be rapid compared to that elsewhere. Were it not, semiconductor producers would be driven out of business by the ever-lower prices for their output in the face of stable input costs. This example illustrates that relative growth rates of sectoral MFP can be inferred from movements in 
relative output prices.

We rely on this link to estimate sectoral MFP growth. Proposition 3 provides the details, which involve some messy algebra. Roughly speaking, each sectoral MFP growth rate can be written as

$$
\dot{M F P} \dot{M}_{i}=\dot{F P}_{O}-\pi_{i}+\text { terms for the relative growth in sectoral input costs, }
$$

where $\pi_{i} \equiv\left(\dot{p_{i}}-\dot{p_{O}}\right)$ denotes the difference in output price inflation between sector $i$ and the "other final-output" sector, which serves as our benchmark sector. If input costs grew at the same rate in every sector, the change in relative output prices would fully characterize the differences in sectoral MFP growth. However, because semiconductors loom large in the cost structure of the computer industry, we know that input costs for that industry are falling relative to those for other sectors. The additional terms in equation 5 take account of these differences in sectoral input costs.

Note that equation 5 determines relative rates of MFP growth, not the absolute rate in any sector. We pin down the absolute MFP growth rates in two different ways, the first of which uses equation 3 to force the sectoral MFP growth rates to reproduce our estimate of aggregate MFP growth. This case represents the methodology we use to compute historical growth contributions through 2001. In the second case, which we use

\footnotetext{
${ }^{6}$ Under perfect competition, the growth rate of MFP in each sector can be inferred exactly from relative price movements. However, if markets are not perfectly competitive, then the dual methodology would yield an inaccurate reading on MFP growth to the extent that relative price changes owed to swings in margins rather than to technological developments. Of course, if there is imperfect competition but margins are constant, then MFP growth rates still can be inferred exactly from relative price movements because changes in margins would not be a source of changes in relative prices. For the semiconductor sector - where market concentration in microprocessors suggests that this potential problem with the dual methodology likely would be particularly acute - Aizcorbe (2002) found that a conventional Tornquist index of Intel microprocessor prices fell 24-1/2 percent per quarter on average from 1993-99. Adjusted for movements in Intel's margins over this period, Aizcorbe found that Intel chip prices declined 21 percent per quarter. Thus, swings in margins appear to have had a relatively small average effect on chip prices over this period.
} 
for our steady-state analysis, we condition on an assumed pace of MFP growth in the "other final-output" sector, which generates the remaining sectoral MFP growth rates via equation 5 and aggregate MFP growth via equation 3.

\section{Analysis of the Steady State}

In addition to explaining the source of the productivity pickup in the 1990s, we wish to estimate a plausible range for productivity growth in the future. To develop such a range, we impose additional "steady-state" conditions on our model, closely following the two-sector analysis in Martin (2001) and Whelan (2001).

Among the conditions imposed to derive steady-state growth, we assume that output in each sector grows at a constant rate (which differs across sectors). In addition, we impose conditions that are sufficient to force investment in each type of capital to grow at the same (constant) rate as the stock of that capital. Taken together, these conditions can be shown to imply that production in each final-output sector grows at the same (constant) rate as the capital stock that consists of investment goods produced by that sector. Two other important conditions are that labor hours grow at the same (constant) rate in each sector and that all income shares and sectoral output shares remain constant.

Under these steady-state conditions, proposition 4 shows that the growthaccounting equation for aggregate labor productivity becomes

$$
\dot{Y}-\dot{H}=\sum_{i=1}^{4}\left(\alpha_{i}^{K} / \alpha^{L}\right)\left(\dot{M F} P_{i}+\beta_{i}^{S} \dot{M F} P_{S}\right)+\dot{q}+\dot{M F P},
$$

where $\dot{M F P}$ is calculated, as above, from equation 3 . Note that equation 6 contains no explicit terms for capital deepening, in contrast to its non-steady-state counterpart, 
equation 1. No such terms appear because the steady-state pace of capital deepening is determined endogenously within the model as a function of the sectoral MFP growth rates. Hence, the summation on the right side of equation 6 represents the growth contribution from this induced capital deepening. With this interpretation, it becomes clear that equations 1 and 6 share a common structure - both indicate that the growth of labor productivity depends on capital deepening, improvements in labor quality, and growth in MFP.

To further interpret equation 6, consider the growth-accounting equation (outside the steady state) for a simple one-sector model:

$$
\dot{Y}-\dot{H}=\alpha^{K}(\dot{K}-\dot{H})+\alpha^{L} \dot{q}+\dot{M F P} .
$$

Now, impose the steady-state condition that output and capital stock grow at the same

rate and substitute $\dot{K}=\dot{Y}$ into equation 7, noting that $\alpha^{K}+\alpha^{L}=1$ under constant returns to scale. The result is

$$
\dot{Y}-\dot{H}=\dot{q}+\dot{M F P} / \alpha^{L}=\left(\alpha^{K} / \alpha^{L}\right) \dot{M F P}+\dot{q}+\dot{M F P},
$$

where the second equality uses the fact that $\left(\alpha^{K} / \alpha^{L}\right)=\left(1 / \alpha^{L}\right)-1$ when $\alpha^{K}+\alpha^{L}=1$.

Comparing equations 6 and 8 shows that our steady-state growth-accounting decomposition is the multi-sector counterpart to the decomposition in a one-sector model.

\section{Summary}

We use equations 1-3 and 5 to decompose the observed growth in labor productivity through 2001. Equation 1 provides the structure for the decomposition, while equation 2 shows how we calculate the income shares, and equations 3 and 5 (implemented with the dual method) shows how we relate aggregate MFP growth to its 
sectoral components. To estimate the growth of labor productivity in the steady state, we replace equation 1 with equation 6 , but otherwise we use the same machinery as for the historical decompositions.

\section{DATA}

This section provides a brief overview of the data used for this paper; a detailed description appears in appendix 2. To estimate the pieces of the decomposition of labor productivity growth, we rely heavily on data from the Bureau of Economic Analysis (BEA) and the Bureau of Labor Statistics (BLS). Our starting point is the dataset assembled by BLS for its estimates of multifactor productivity. These annual data cover the private nonfarm business sector in the United States and provide measures of the growth of real output, real capital input, labor hours, and labor quality. At the time we were writing, the BLS dataset ran through 2000, and we extended all necessary series through 2001.

The income shares in our growth-accounting calculations depend on estimates of the gross rate of return earned by each asset $\left(R+\delta_{j}-\Pi_{j}\right)$. To measure the components of the gross return, we rely again on data from BEA and BLS. With just a few exceptions,

the depreciation rates $\left(\delta_{\mathrm{j}}\right)$ for the various types of equipment, software, and structures are those published by BEA. Because BEA provides only limited information on the depreciation rates for components of computers and peripheral equipment, we follow Whelan (2000) and set these depreciation rates equal to a geometric approximation calculated from BEA capital stocks and investment flows. For personal computers, we are uncomfortable with BEA's procedure, and instead set the depreciation rate for PCs equal to the 30 percent annual rate for mainframe computers. (See appendix 2 for a 
discussion of this issue.) To estimate the capital gain or loss term in the gross return $\left(\Pi_{\mathrm{j}}\right)$, we use a three-year moving average of the percent change in the price of each asset. The moving average smooths the often volatile yearly changes in prices and probably conforms more closely to the capital gain or loss that asset owners expect to bear when they make investment decisions. Finally, to calculate the net return (R), we mimic the BLS procedure, which computes the average realized net return on the entire stock of equipment, software, and structures. By using this average net return in the income share for each asset, we impose the neoclassical assumption that all types of capital earn the same net return in a year.

To implement the sectoral model of MFP, we need data on final sales of computer hardware, software, and communication equipment, as well as data on the semiconductor sector. Our data on final sales of computer hardware came from the National Income and Product Accounts, and we used unpublished BEA data to calculate final sales of software and communication equipment. For the semiconductor sector, we used data from the Semiconductor Industry Association as well as data constructed by Federal Reserve Board staff to support the Fed's published data on U.S. industrial production.

\section{DECOMPOSITION OF LABOR PRODUCTIVITY GROWTH}

As discussed above, our earlier research documented that information technology was a key driver behind the resurgence in labor productivity growth during the second half of the 1990s. Recent developments - including the bursting of the Nasdaq bubble and the dramatic retrenchment in the high-tech sector - have raised questions about the robustness of those results. By extending our estimates through 2001, we can assess 
whether the latest data still support the basic story in our earlier research. We describe our new numbers and then compare them to our earlier results.

\section{Results Through 2001}

Table 1 presents our decomposition of labor productivity growth in the nonfarm business sector through 2001. As shown in the first line of the table, growth in labor productivity picked up from about 1.5 percent per year in the first half of the 1990 s to about 2.4 percent since $1995 .^{\square}$ Rapid capital deepening related to information technology capital - the greater use of information technology - accounted for about three-fifths of this pickup (line 3 ) ${ }^{8}$ Other types of capital (line 7) made a much smaller contribution to the acceleration in labor productivity, while the contribution from labor quality actually fell across the two periods. This leaves multifactor productivity (line 9) to account for a little less than half of the improvement in labor productivity growth.

Next, we decompose this overall MFP contribution into its sectoral components in order to estimate the growth contribution from the production of information technology. Lines 10-14 of table 1 display this sectoral decomposition. The results show that the MFP contribution from semiconductor producers (line 10) jumped after 1995. Given our use of the "dual" methodology, this pickup owes to the more rapid decline in

\footnotetext{
${ }^{7}$ Note that the figures for output per hour in table 1 are based on the BLS published series for nonfarm business output. This series is a "product-side" measure of output, which reflects spending on goods and services produced by nonfarm businesses. Alternatively, output could be measured from the "income side" as the sum of payments to capital and labor employed in that sector. Although the two measures of output differ only slightly on average over long periods of time, a sizable gap has emerged in recent years. By our estimates, the acceleration in the income-side measure was about $1 / 3$ percentage point greater (at an average annual rate) after 1995 . We employ the published product-side data to maintain consistency with other studies; in addition, if an adjustment were made to output and labor productivity growth, it is not clear how that adjustment should be allocated among the components of capital deepening and MFP growth. Nonetheless, the true pickup in productivity growth after 1995 could be somewhat larger than shown in our table.

${ }^{8}$ As described in appendix 2, there is some evidence that BEA may revise down its figures for software spending in the next NIPA benchmark revision. If such a revision were to occur, the software contributions to growth displayed on line 5 would be reduced.
} 
semiconductor prices in this period, which the model interprets as a speed-up in MFP growth. In contrast, the MFP contribution from the other information technology sectors taken together (lines 11-13) rose only a little after 1995 compared with the first half of the 1990s.

For computer hardware, the particularly rapid decline in prices after 1995 might have led one to believe that MFP growth in this sector had increased dramatically. However, as indicated earlier, the computer sector - as we define it - excludes the production of the semiconductors embedded in computer hardware. Thus, MFP in the computer sector represents only efficiency gains in the design and assembly of computers, not in the production of the embedded semiconductors. Accordingly, our results indicate that the faster declines in computer prices after 1995 largely reflected the sharp drop in the cost of semiconductor inputs rather than independent developments in computer manufacturing.

The MFP contributions from the software and communication equipment sectors were fairly small during both 1991-95 and 1996-2001. According to the published numbers, the relative prices of both software and communication equipment fell much less rapidly than did relative computer prices during these periods. ${ }^{\natural}$ In addition, for communication equipment, our numbers indicate that much of the relative price drop that

\footnotetext{
${ }^{9}$ Jorgenson and Stiroh (2000) raised the possibility that software prices may have fallen faster than reported in the official numbers. While this may be correct, software has historically been a craft industry, in which highly skilled professionals write code line by line. In the 1960s and 1970s, several studies examined costs per line of code written. Phister (1979, p. 502) estimated a 3.5 percent annual reduction in the labor required to produce one thousand lines of code. Zraket (1992) argued that the nominal cost per line of code in the early 1990s was little changed from twenty years earlier, which would yield a real decline similar to Phister's. Of course, the more recent adoption of suites, licenses, and enterprise-wide software solutions may well have led to dramatic declines in the effective price of software. All told, we believe that considerable uncertainty still attends the measurement of software prices.

Jorgenson and Stiroh (2000) also suggested that prices of communication equipment may have fallen faster than reported in official statistics. Recent work by Doms (2002) provides support for that perspective.
} 
did occur reflected the plunging costs of semiconductor inputs, which our sectoral decomposition attributes to MFP growth in the semiconductor industry, not in communication equipment. Thus, the "dual" methodology suggests that the MFP gains in both software and communication equipment have been far smaller than those in the computer sector.

Putting together the information technology pieces (line 15), greater use of information technology and faster efficiency gains in the production of information technology more than accounted for the 0.89 percentage point speed-up in labor productivity growth after 1995 . This large contribution can also be seen in figure 1; the dark bars show the contribution from the use of IT and the light bars show the contribution from the production of IT on a year-by-year basis. As the figure shows, these contributions surged after 1995. Although they dropped back in 2001, the contributions for that year remain well above those observed before 1995. Based on these results, we conclude that the latest data confirm the main findings in our earlier work. Namely, the resurgence in labor productivity is still quite evident in the data, and information technology appears to have played a central role in this pickup.

\section{Further Comparison to Our Earlier Work}

Table 2 compares our latest numbers to those in Oliner and Sichel (2000a). ${ }^{10}$ The first column of the table shows contributions to the pickup in labor productivity growth from our earlier paper, the second column presents estimates through 2000 using the latest data, and the third column repeats the contributions through 2001 shown in table 1. In addition to the inclusion of data for 2000 , the numbers in the second column differ

\footnotetext{
${ }^{10}$ This table shows separate MFP contributions only for the semiconductor and computer sectors to maintain comparability with our earlier work.
} 
from those in the first because there have been several data revisions since our earlier results were completed. ${ }^{11}$ As can be seen from these columns, incorporating data for 2000 and revisions for earlier years changed our results relatively little. The contribution to the productivity pickup from software capital deepening increased, but this was offset by a more negative contribution from labor quality and a somewhat smaller contribution from MFP growth.

Extending the results through the recession year 2001 tempers the step-up in labor productivity growth (line 1), as would be expected given the procyclical behavior of productivity gains. At the same time, line 2 indicates that the growth contribution from capital deepening increased with the inclusion of data for 2001. The large implied contribution in 2001 may seem puzzling in light of the recession-related downturn in investment spending. However, recall that capital deepening reflects the ratio of capital services to hours worked. Hours declined in 2001, which - all else equal - boosts the capital-hours ratio. Also, note that our growth accounting uses annual-average data. Because investment spending weakened over the course of 2001, annual averaging smooths this decline relative to the change observed over the four quarters of the year. Similarly, the Tornquist weighting procedure delays the impact of such changes by using an average of this year's and last year's capital income shares as aggregation weights for the capital deepening contributions. Thus, some of the effects of the recession on corporate profits (and hence on the capital income shares) will not show up in our

\footnotetext{
${ }^{11}$ The most important data revisions since we finished the work for Oliner and Sichel (2000a) have been the two annual NIPA revisions released by BEA - which are fully reflected in the latest BLS multifactor productivity data - and the inclusion of official estimates of capital stocks for software. (In our earlier work, we had included our own estimate of software capital stocks.) In addition, we have made some minor adjustments to our estimation procedures, but these changes had relatively small effects.
} 
numbers until 2002. Indeed, a back-of-the-envelope calculation suggests that the contribution of capital deepening will drop back in 2002.

The final effect of folding in data for 2001 is the noticeably smaller contribution of MFP to the post-1995 step-up in labor productivity growth (line 9). Virtually the entire effect resides in the large residual sector consisting of all nonfarm business except the computer and semiconductor industries (line 12).

Some observers might argue that the very small acceleration of MFP outside these IT-producing sectors indicates that the productivity benefits of IT have been either narrowly focused or have been largely reversed over the past year. However, we are not inclined to accept either interpretation for two reasons. First, the use of IT throughout the economy has contributed significantly to the pickup in labor productivity growth, quite apart from developments in IT-producing industries. Second, the much-reduced MFP acceleration in other industries likely reflected cyclical factors. ${ }^{3}$ Identifying the magnitude of such cyclical influences is challenging, and we believe that the trend cannot be inferred from the average growth rate between 1995 and 2001. The first year of that period, 1995, was midway through the cycle, while the last year, 2001, was a recession year. 14 Thus, taking an average over 1995-2001 implicitly draws a line from a point at

\footnotetext{
${ }^{12}$ To show this, we calculated capital deepening for 2002 on the assumption that the growth rate of real investment in high-tech equipment snaps back to its robust average pace during 1996-2000 and that hours fall nearly 1 percent in 2002 on an annual-average basis as projected in Macro Advisers' January Economic Outlook. Even under this optimistic assumption for investment and sluggish forecast for hours, the contribution of capital deepening to labor productivity growth in 2002 would be below its 2001 value, but still significantly above its pre-1995 value.

${ }^{13}$ Even though MFP is often associated with technological change, short-run movements in MFP can be heavily influenced by cyclical factors that have little relation to technological change. For further discussion of this point, see Basu, Fernald, and Shapiro (2001).

${ }^{14}$ Inferring the trend from the average growth rate between 1995 and 2000 also may be problematic because the average covers a period from mid-cycle to peak. But, moving the initial year back to the prior peak in 1990 is not appealing because we are interested in what happened to productivity beginning in the mid-1990s.
} 
mid-cycle to a point near the bottom of the cycle. Such a line likely understates the trend over this period.

\section{LABOR PRODUCTIVITY GROWTH IN THE STEADY STATE}

How much of the resurgence in labor productivity growth in the second half of the 1990s is sustainable? To address this question, we use the steady-state machinery described in section 2 to generate a range of likely outcomes for labor productivity growth in the future. We do not regard these steady-state results as forecasts of productivity growth for any particular time period. Rather, this exercise yields "structured guesses" of the sustainable growth in labor productivity consistent with alternative scenarios for the evolution of key features of the economy.

To construct this range of likely outcomes, we set lower and upper bounds on steady-state parameters and then solve for the implied rates of labor productivity growth. We believe that these scenarios encompass the most plausible paths going forward, but there is substantial uncertainty about future productivity developments. Hence, as we will discuss, the sustainable pace of labor productivity growth could fall outside the range that we consider most likely. The rest of this section describes the lower and upper bound parameter values that we chose, presents our steady-state results, and compares our results to those obtained by other researchers.

\section{Parameter Values}

Table 3 displays the many parameters that feed into our model of steady-state growth. To provide some historical context, the first three columns of the table show the average value of each parameter over 1974-90, 1991-95, and 1996-2001. The next two 
columns present our assumed lower-bound and upper-bound values for each parameter in the steady state, and the final column briefly indicates the rationale for these steady-state values.

Lines 1-15 of the table list the parameters needed to compute aggregate and sectoral MFP growth in the steady state. These parameters include each sector's currentdollar share of nonfarm business output (the $\mu$ 's), outlays for semiconductors as a share of total input costs in each final-output sector (the $\beta$ 's), the rate of output price inflation in each sector relative to that in the "other final-output" sector (the $\pi$ 's), and the growth of MFP in the "other final output" sector $\left(M F P_{O}\right)$.

Although the steady-state bounds for some of these parameters require no discussion beyond the brief rationale in the table, others need further explanation. 16 Starting with the output shares, we calibrated the steady-state bounds from the plots in figure 2. The short lines in each panel represent the bounds, which can be compared to the history for each series. The current-dollar output shares for producers of computer hardware and communication equipment have each fluctuated in a fairly narrow range since the mid-1980s. Our steady-state bounds largely bracket those ranges. For producers of software and semiconductors, the current-dollar output shares have trended sharply higher over time, and our steady-state bounds allow for some additional increase

\footnotetext{
${ }^{15}$ Note that the upper-bound value for each parameter yields a higher rate of productivity growth than the lower-bound value. For some parameters, such as relative prices, the upper-bound value is numerically smaller than the lower-bound value.

${ }^{16}$ In performing similar exercises, DeLong (2002), Kiley (2001), and Martin (2001) start with demand elasticities for high-tech products to generate output and income shares. In contrast, we set assumptions for output shares and other key parameters directly. Because relatively little is known about high-tech demand elasticities, we prefer the transparency of directly setting output shares and other parameters based on their historical patterns.
} 
from the average level in recent years.

Among the semiconductor cost shares (the $\beta$ 's), we set the share for computers equal to 0.30 , the middle of the range employed by Triplett (1996). For software, we set the share to zero. The share for communication equipment is shown in figure 3. This share has risen quite a bit since the early 1990s, reflecting the increasing concentration of computer-like technology in communication equipment. We set the steady-state bounds on the assumption that this trend will persist.

This increase in the semiconductor content of communication equipment implies that the relative price for such equipment is likely to fall more rapidly in the future than it has over history. We built that expectation into the steady-state bounds for $\pi_{M}$, shown on line 14. These values were chosen to ensure that the implied MFP growth rate for the sector, computed by the dual method, remained close to the average pace over 19962001.

This issue does not arise for the other final-output sectors, where the semiconductor cost shares are assumed to change little, if at all, going forward. For these sectors (lines 11-13), we set the bounds on relative price changes (the $\Pi$ 's) by reference to historical patterns. The lower bound for each sector equals the average rate of relative price change over 1974-2001, while the upper bound lies midway between that average and the most rapid rate of relative price decline for the three subperiods since 1974. Thus, we do not assume that the extremely rapid declines in computer and semiconductor prices over 1996-2001 will persist in the steady state, even in our optimistic scenario.

Lines 16-28 of the table list the components of the capital income shares. For the

\footnotetext{
${ }^{17}$ The output share for the semiconductor sector plunged in 2001 to the lowest level since 1994 owing to the deep cutbacks in spending on high-tech equipment during the recession. In setting the steady-state bounds, we assumed that the cyclical drop would be reversed as the economy recovers from recession.
} 
nominal rate of return on capital and the asset-specific depreciation rates, we simply project forward the average values for 1996-2001. These parameters varied only slightly between the first and second halves of the 1990s; moreover, the higher nominal return on capital over 1974-90, which was driven in part by the elevated pace of inflation over that period, is not appropriate for the current low-inflation environment. For the next element of the income share, the expected capital gain or loss on the asset, we set the steady-state bounds in essentially the same way as we did for the relative inflation rates. For all types of capital except communication equipment, we chose these bounds by reference to the historical data, though we looked back only to 1991 to avoid building in the higher rates of inflation that prevailed over 1974-90. The bounds for communication equipment were set to the analogous bounds for the relative price decline on line 14, plus two percentage points. This add-on for the assumed rate of inflation in the "other final-output" sector converts the relative price change into an absolute change.

The final piece of the income share is the (tax-adjusted) capital-output ratio, expressed in current dollars $\left(T p_{K} K / p Y\right)$. Figure 4 displays this ratio back to 1974 for the four types of capital. For computer hardware and communication equipment, where the capital-output ratio has not displayed a clear trend of late, we set the bounds to keep the ratio in its neighborhood of recent years. In contrast, for software and other fixed capital, we chose the bounds to allow for a continuation of longer-term trends. Figure 5 shows the implied bounds for the capital income shares, along with the historical series for these shares. The one series that bears comment is the share for other equipment and nonresidential structures, which plummeted in 2001, as the recession-induced decline in 
corporate profits depressed the nominal return to capital $(R) .18$ The steady-state bounds

for this income share imply at least a partial reversal of this cyclical decline.

The final parameter of note is the growth of labor quality (line 35). We assume that labor quality will increase 0.30 percent per year in steady state, noticeably slower than its average annual rise since 1959. Jorgenson, Ho, and Stiroh (2002) suggest a stepdown in labor quality growth of similar magnitude, while Aaronson and Sullivan (2001) project a slightly larger drop-off in labor quality growth going forward.

\section{Results}

Table 4 contains the "structured guesses" of labor productivity growth in the steady state using lower-bound and upper-bound parameter values. ${ }^{19}$ As shown on line 1 , the lower-bound parameter values generate steady-state growth in labor productivity of about 2 percent, while the upper-bound values imply growth of slightly more than $2-3 / 4$ percent. 20 This range, which sits well above the sluggish pace realized from the early 1970s to the mid-1990s, suggests a relatively optimistic outlook for labor productivity.

To provide intuition for the steady-state range, note that the lower-bound figure of about 2 percent is roughly $1 / 2$ percentage point below the pace of labor productivity

\footnotetext{
${ }^{18}$ The drop in $R$ had a much greater effect on the income share for this broad capital aggregate than on the income shares for computers, software, or communication equipment. For these high-tech assets, the rapid trend rate of depreciation is the dominant piece of the gross return, overwhelming even sizable movements in $R$.

${ }^{19}$ As noted in section 2, our model does not explicitly account for adjustment costs. Nevertheless, we recognize that such costs could have important implications for labor productivity growth, as emphasized by Kiley (2001) and Basu, Fernald, and Shapiro (2001). And, implicitly, our steady-state estimates of labor productivity growth embed the average historical value of adjustment costs. Specifically, if adjustment costs have held down labor productivity growth on average historically, our growth-accounting framework will sweep these effects into the residual - which is MFP growth in "other final output." Because our steady-state estimates depend on MFP growth in that residual category, the average historical magnitude of adjustment costs is implicitly built into these estimates.

${ }^{20}$ It is reassuring that the results generated by the steady-state model over historical periods are well aligned with measured productivity growth. In particular, if we use the steady-state model with the historical average parameter values in table 3 , it returns an average growth rate for labor productivity of 1.57 percent over 1974-2001, very close to the actual growth rate of 1.62 percent over this period.
} 
growth during 1996-2001. This slowdown occurs because we assume that the rates of decline in semiconductor and computer prices revert to their long-run historical averages from the very rapid pace realized in the second half of the 1990s. These assumptions produce a marked slowdown in MFP growth in the semiconductor sector and, to a lesser extent, in the computer sector. Nonetheless, labor productivity growth for nonfarm business as a whole remains above the 1974-95 average because the IT sectors, taken together, constitute a larger part of the economy than they did in this earlier period.

The upper-bound figure of about 2.8 percent in steady state is almost $1 / 2$ percentage point above the 1996-2001 pace. The model generates this step-up even though the price declines for semiconductors and computers in steady state (and hence the rates of MFP growth) are assumed to be less rapid than those in the second half of the 1990s. The countervailing factor is that the semiconductor sector and other IT sectors grow as a share of the economy compared to the second half of the 1990s. The greater importance of these sectors with relatively fast MFP growth more than makes up for the slower price declines for semiconductors and computers.

The remaining lines of table 4 decompose steady-state growth in labor productivity into induced capital deepening and MFP growth. These numbers highlight the important role of IT in future labor productivity growth. In particular, a comparison of lines 2 and 3 indicates that the induced capital deepening in steady state is very heavily skewed toward IT capital in both the lower- and upper-bound scenarios, just as it was in the latter half of the 1990s. More broadly, as shown on line 7, the combined contribution of both the induced use and the production of IT accounts for about three-fourths of overall labor productivity growth in both the lower- and upper-bound scenarios. 
As indicated above, our intent is to provide a likely range for steady-state growth in labor productivity, not to bound all possible outcomes. For example, the steady-state model can generate labor productivity growth above 3 percent per year if we assume that semiconductor and computer prices continue to fall at the 1996-2001 pace and allow the semiconductor output share to rise by the amount seen between the first and second halves of the 1990s. Conversely, we can generate numbers for labor productivity growth between $1-1 / 2$ and $1-3 / 4$ percent per year if we assume that price declines for computers and semiconductors revert to their historical average and that the computer and semiconductor output shares go back down to levels seen in the first half of the 1990s. So, while we are comfortable with a likely range for steady-state labor productivity growth from 2 percent to $2-3 / 4$ percent, we are well aware of the uncertainty that attends the exercise we have undertaken.

\section{Comparison to Other Research}

Table 5 compares the steady-state results in this paper to those obtained by other researchers. There are two points to take away from this table. First, the range of estimates is very wide, extending from about $1-1 / 4$ percent up to $3-1 / 4$ percent. This range highlights the uncertainty surrounding the future path of productivity growth. Second, despite the wide band of uncertainty, most of the point estimates (or range midpoints) fall within our range of 2 to $2-3 / 4$ percent per year. Thus, there is considerable agreement among researchers that productivity growth likely will remain fairly strong going forward. 


\section{CONCLUSION}

Recent debates about the pickup of productivity growth in the United States have revolved around two questions. First, are the results from earlier research that emphasized the role of IT still valid given the sharp contraction in the technology sector? Second, how much of the improvement in labor productivity growth since the mid-1990s could plausibly be sustained? This paper addressed both questions.

As for the robustness of earlier results, we used data through 2001 to reassess the role of information technology in the productivity revival since the mid-1990s. These new growth-accounting results indicate that the story told in Oliner and Sichel (2000a) still stands. Namely, output per hour accelerated substantially after 1995, driven in large part by greater use of IT capital goods by businesses all throughout the economy and by more rapid efficiency gains in the production of IT goods.

To address the question of sustainability, we analyzed the steady-state properties of a multi-sector growth model. This framework translates alternative views about the evolution of the technology sector and other features of the economy into estimates of labor productivity growth in the steady state. When we imposed relatively conservative values for key parameters, this framework generated steady-state growth in labor productivity of about 2 percent per year. This estimate rose to roughly $2-3 / 4$ percent when we imposed somewhat more optimistic assumptions. We refer to these estimates as structured guesses, and think of them as identifying a likely range of productivity outcomes over roughly the next decade. Of course, any such exercise entails substantial uncertainty, and we also discussed scenarios that would generate a wider range of outcomes. 
Our analysis highlights that future increases in output per hour will depend importantly on the pace of technological advance in the semiconductor industry and on the extent to which products embodying these advances diffuse through the economy. This observation is consistent with the emphasis in Jorgenson (2001) on semiconductor technology. Gaining a deeper understanding of technological developments in this sector should be a high priority for those attempting to shed light on trends in productivity. 


\section{REFERENCES}

Aaronson, Daniel and Daniel Sullivan. 2001. Growth in worker quality. Federal Reserve Bank of Chicago Economic Perspectives 25, Fourth Quarter: 53-74.

Aizcorbe, Ana. 2002. Why are semiconductor prices falling so fast? Industry estimates and implications for productivity measurement. Federal Reserve Board. Finance and Economics Discussion Series Paper 2002-20. March. WwW.federalreserve.gov/pubs/feds/200220/200220pap.pdf .

Baily, Martin Neil. 2002. The new economy: Post mortem or second wind? Institute for International Economics. Unpublished paper. January 10.

Basu, Susanto, John G. Fernald, and Matthew D. Shapiro. 2001. Productivity growth in the 1990s: Technology, utilization, or adjustment? Carnegie-Rochester Conference Series on Public Policy 55: 117-165.

Bosworth, Barry P. and Jack E. Triplett. 2000. What is new about the new economy? Information technology, economic growth, and productivity. Unpublished paper. The Brookings Institution.

Congressional Budget Office. 2002. The Budget and Economic Outlook: Fiscal Years 2003-2012. January. <www.cbo.gov>. (Accessed: March 26, 2002).

DeLong, J. Bradford. 2002. Productivity growth in the 2000s. Unpublished paper. University of California at Berkeley.

Domar, Evsey. 1961. On the measurement of technological change. Economic Journal 71, December: 309-29.

Doms, Mark. 2002. Communications equipment: What has happened to prices? Unpublished paper. Federal Reserve Board.

Economic Report of the President. 2002. Washington, D.C.: U.S. Government Printing Office.

Economic Report of the President. 1999. Washington, D.C.: U.S. Government Printing Office.

Flamm, Kenneth. 1997. More for less: The economic impact of semiconductors. December. Semiconductor Industry Association.

Fraumeni, Barbara M. 1997. The measurement of depreciation in the U.S. national income and product accounts. Survey of Current Business 77, July: 7-23. 
Gordon, Robert J. 2002. Technology and economic performance in the American economy. National Bureau of Economic Research. Working paper no. 8771.

Gordon, Robert J. 2000. Does the 'new economy' measure up to the great inventions of the past? Journal of Economic Perspectives 14, Fall: 49-74.

Grimm, Bruce. 1998. Price indexes for selected semiconductors, 1974-96. Survey of Current Business 78, February: 8-24.

Herman, Shelby. 2000. Fixed assets and consumer durable goods. Survey of Current Business 80, April: 17-30.

Hulten, Charles R. 1978. Growth accounting with intermediate inputs. The Review of Economic Studies 45, October: 511-18.

Jorgenson, Dale W. 2001. Information technology and the U.S. economy. American Economic Review 91, March: 1-32.

Jorgenson, Dale W. and Kevin J. Stiroh. 2000. U.S. economic growth in the new millenium. Brookings Papers on Economic Activity 1, pp. 125-211.

Jorgenson, Dale W., Mun S. Ho, and Kevin J. Stiroh. 2002. Projecting productivity growth: Lessons from the U.S. growth resurgence. This volume.

Kiley, Michael T. 2001. Computers and growth with frictions: Aggregate and disaggregate evidence. Carnegie-Rochester Conference Series on Public Policy 55: 171215.

Macroeconomic Advisers. 2002. Economic Outlook. St. Louis, Missouri. January.

Martin, Bill. 2001. American potential. UBS Asset Management. May. $<$ www.phillipsdrew.com/research/american_potential.pdf>. (Accessed: March 26, 2002).

McKinsey Global Institute. 2001. US productivity growth 1995-2000: Understanding the contribution of information technology relative to other factors. Washington, D.C.: McKinsey Global Institute. October.

Moylan, Carol. 2001. Estimation of software in the U.S. national accounts: New developments. Organization for Economic Cooperation and Development, STD/NA(2001)25, September 24, 2001.

Oliner, Stephen D. 1994. Measuring stocks of computer peripheral equipment: Theory and application. Unpublished paper. Federal Reserve Board. 
Oliner, Stephen D. and Daniel E. Sichel. 2000a. The resurgence of growth in the late 1990s: Is information technology the story? Journal of Economic Perspectives 14, Fall: 3-22.

Oliner, Stephen D. and Daniel E. Sichel. 2000b. The resurgence of growth in the late 1990s: Is information technology the story? Federal Reserve Board. Finance and Economics Discussion Series Paper 2000-20. May.

$<$ www.federalreserve.gov/pubs/feds/2000/200020/200020pap.pdf $>$.

Parker, Robert and Bruce Grimm. 2000. Software prices and real ouptut: Recent developments at the Bureau of Economic Analysis. Bureau of Economic Analysis. Unpublished paper. April.

Roberts, John M. 2001. Estimates of the productivity trend using time-varying parameter techniques. Contributions to Macroeconomics 1, no. 1. $<$ www.bepress.com/bejm/contributions/vol1/iss1/art3>. (Accessed: March 26, 2002).

Sichel, Daniel E. 1997. The Computer Revolution: An Economic Perspective. Washington, D.C.: The Brookings Institution.

Solow, Robert. 1957. Technical change and the aggregate production function. Review of Economics and Statistics 39, August: 65-94.

Steindel, Charles and Kevin J. Stiroh. 2001. Productivity growth: What is it and why do we care about it? Business Economics 36, October: 13-31.

Triplett, Jack E. 1996. High-tech industry productivity and hedonic price indices. In Industry Productivity: International Comparison and Measurement Issues, Proceedings of May 2-3, 1996 OECD workshop, 119-42. Paris: Organisation for Economic Cooperation and Development.

Whelan, Karl. 2001. A two-sector approach to modeling U.S. NIPA data. Federal Reserve Board. Finance and Economics Discussion Series Paper 2001-4. April. $<$ www.federalreserve.gov/pubs/feds/2001/200104/200104pap.pdf $>$.

Whelan, Karl. 2000. Computers, obsolescence, and productivity. Federal Reserve Board. Finance and Economics Discussion Series Paper 2000-6. February. $<$ www.federalreserve.gov/pubs/feds/2000/200006/200006pap.pdf>.

Whelan, Karl. 1999. Tax incentives, material inputs, and the supply curve for capital equipment. Federal Reserve Board. Finance and Economics Discussion Series Paper 1999-21. April. <www.federalreserve.gov/pubs/feds/1999/199921/199921 pap.pdf>. 


\section{Table 1}

\section{Contributions to Growth in Labor Productivity, Using Latest Data}

\begin{tabular}{|c|c|c|c|c|c|}
\hline & & $\begin{array}{c}1974- \\
1990 \\
(1) \\
\end{array}$ & $\begin{array}{c}1991- \\
1995 \\
(2) \\
\end{array}$ & $\begin{array}{c}1996- \\
2001 \\
(3) \\
\end{array}$ & $\begin{array}{l}\text { Post-1995 } \\
\text { change } \\
\text { (3) minus (2) }\end{array}$ \\
\hline \multicolumn{2}{|c|}{ 1. Growth of labor productivity ${ }^{1}$} & 1.36 & 1.54 & 2.43 & .89 \\
\hline \multicolumn{6}{|c|}{ Contributions from: ${ }^{2}$} \\
\hline 2. & Capital deepening & .77 & .52 & 1.19 & .67 \\
\hline 3. & Information technology capital & .41 & .46 & 1.02 & .56 \\
\hline 4. & Computer hardware & .23 & .19 & .54 & .35 \\
\hline 5. & Software & .09 & .21 & .35 & .14 \\
\hline 6. & Communication equipment & .09 & .05 & .13 & .08 \\
\hline 7. & Other capital & .37 & .06 & .17 & .11 \\
\hline 8. & Labor quality & .22 & .45 & .25 & -.20 \\
\hline 9. & Multifactor productivity & .37 & .58 & .99 & .41 \\
\hline 10. & Semiconductors & .08 & .13 & .42 & .29 \\
\hline 11. & Computer hardware & .11 & .13 & .19 & .06 \\
\hline 12. & Software & .04 & .09 & .11 & .02 \\
\hline 13. & Communication equipment & .04 & .06 & .05 & -.01 \\
\hline 14. & Other sectors & .11 & .17 & .23 & .06 \\
\hline
\end{tabular}

Memo:
15. Total IT contribution ${ }^{3}$
.68
.87
1.79
.92

1. In the nonfarm business sector. Measured as average annual log difference for years shown multiplied by 100 .

2. Percentage points per year.

3. Equals the sum of lines 3 and 10-13.

Note: Detail may not sum to totals due to rounding.

Source: Authors' calculations based on BEA and BLS data. 


\section{Table 2}

\section{Acceleration in Labor Productivity between 1991-95 and Post-1995 Period, Effect of New Data and Revisions}

\begin{tabular}{|c|c|c|c|}
\hline & $\begin{array}{c}J E P \text { Paper } \\
\text { Through } 1999 \\
\end{array}$ & $\begin{array}{c}\text { This Paper } \\
\text { Through } 2000 \\
\end{array}$ & $\begin{array}{c}\text { This Paper } \\
\text { Through } 2001 \\
\end{array}$ \\
\hline 1. Acceleration in labor productivity ${ }^{1}$ & 1.04 & 1.00 & .89 \\
\hline \multicolumn{4}{|l|}{ Contributions from: ${ }^{2}$} \\
\hline 2. Capital deepening & .48 & .57 & .67 \\
\hline Information technology capital & .45 & .54 & .56 \\
\hline Computer hardware & .36 & .36 & .35 \\
\hline Software & .04 & .13 & .14 \\
\hline Communication equipment & .05 & .07 & .08 \\
\hline Other capital & .03 & .02 & .11 \\
\hline 8. Labor quality & -.13 & -.20 & -.20 \\
\hline 9. Multifactor productivity & .68 & .62 & .41 \\
\hline 10. Semiconductors & .27 & .30 & .29 \\
\hline Computer hardware & .10 & .06 & .06 \\
\hline Other sectors ${ }^{3}$ & .31 & .26 & .06 \\
\hline
\end{tabular}

1. In the nonfarm business sector. Measured as percentage points per year.

2. Percentage points per year.

3. Includes producers of communication equipment and software.

Note: Detail may not sum to totals due to rounding.

Source: Authors' calculations based on BEA and BLS data. 
Table 3

\section{Parameter Values for Steady-State Calculations}

\begin{tabular}{|c|c|c|c|c|c|c|}
\hline \multirow[b]{2}{*}{ Parameter } & \multicolumn{3}{|c|}{ Historical Averages } & \multicolumn{2}{|c|}{ Steady-State Values } & \multirow[b]{2}{*}{$\begin{array}{l}\text { Method for Setting } \\
\text { Steady-State Values }\end{array}$} \\
\hline & $\begin{array}{l}1974- \\
1990 \\
\end{array}$ & $\begin{array}{l}1991- \\
1995 \\
\end{array}$ & $\begin{array}{l}1996- \\
2001\end{array}$ & $\begin{array}{l}\text { Lower } \\
\text { Bound }\end{array}$ & $\begin{array}{l}\text { Upper } \\
\text { Bound }\end{array}$ & \\
\hline \multicolumn{7}{|l|}{ Output shares ${ }^{1}(\mu)$} \\
\hline 1. Computer hardware & 1.06 & 1.19 & 1.32 & 1.10 & 1.40 & See figure 2. \\
\hline 2. Software & .84 & 1.79 & 2.70 & 3.10 & 3.60 & See figure 2. \\
\hline 3. Communication equipment & 1.80 & 1.68 & 1.83 & 1.60 & 2.00 & See figure 2. \\
\hline 4. Other final-output sectors & 96.33 & 95.45 & 94.14 & 94.20 & 93.00 & Implied by lines $1-3$ and 5 . \\
\hline 5. Net exports of semiconductors & -.04 & -.11 & .00 & .00 & .00 & 1996-2001 average. \\
\hline 6. Total semiconductor output & .30 & .58 & .91 & 1.00 & 1.20 & See figure 2. \\
\hline \multicolumn{7}{|l|}{ Semiconductor cost shares ${ }^{1}(\beta)$} \\
\hline 7. Computer hardware & 30.00 & 30.00 & 30.00 & 30.00 & 30.00 & Assumed constant value. \\
\hline 8. Software & .00 & .00 & .00 & .00 & .00 & Assumed constant value. \\
\hline 9. Communication equipment & 1.17 & 4.59 & 8.88 & 13.00 & 16.00 & See figure 3. \\
\hline 10. Other final-output sectors & .00 & .27 & .37 & .46 & .46 & Implied by lines $1-4,6-9$, and 36 . \\
\hline \multicolumn{7}{|l|}{ Relative inflation $\operatorname{rates}^{2}(\pi)$} \\
\hline 11. Semiconductors & -28.90 & -21.75 & -44.71 & -31.01 & -37.86 & Lower bound is $1974-2001$ average; \\
\hline 12. Computer hardware & -19.29 & -17.79 & -27.15 & -20.71 & $-23.93 \Rightarrow$ & upper bound is midway between that \\
\hline 13. Software & -4.13 & -4.83 & -3.90 & -4.21 & $-4.52)$ & value and fastest historical decline. \\
\hline 14. Communication equipment & -2.44 & -4.06 & -5.80 & -6.00 & -7.75 & $\begin{array}{l}\text { Calibrated to keep the sector's } M F P \\
\text { growth rate near the } 1996-2001 \text { pace. }\end{array}$ \\
\hline 15. Growth of $M F P_{O}{ }^{3}$ & .11 & .17 & .23 & .11 & .23 & Used historical range. \\
\hline
\end{tabular}

Footnotes are at the end of the table. 
Table 3, continued

\begin{tabular}{|c|c|c|c|c|c|c|}
\hline \multirow[b]{2}{*}{$\underline{\text { Parameter }}$} & \multicolumn{3}{|c|}{ Historical Averages } & \multicolumn{2}{|c|}{ Steady-State Values } & \multirow[b]{2}{*}{$\begin{array}{l}\text { Method for Setting } \\
\text { Steady-State Values }\end{array}$} \\
\hline & $\begin{array}{l}1974- \\
1990 \\
\end{array}$ & $\begin{array}{l}1991- \\
1995 \\
\end{array}$ & $\begin{array}{l}1996- \\
2001 \\
\end{array}$ & $\begin{array}{l}\text { Lower } \\
\text { Bound }\end{array}$ & $\begin{array}{l}\text { Upper } \\
\text { Bound } \\
\end{array}$ & \\
\hline 16. Nominal return on capital ${ }^{3}(R)$ & 7.88 & 4.29 & 4.55 & 4.55 & 4.55 & 1996-2001 average. \\
\hline \multicolumn{7}{|l|}{${\text { Depreciation } \text { rates }^{3}(\delta)}$} \\
\hline 17. Computer hardware & 29.74 & 30.11 & 30.30 & 30.30 & 30.30 & 1996-2001 average. \\
\hline 18. Software & 34.87 & 37.04 & 38.46 & 38.46 & 38.46 & 1996-2001 average. \\
\hline 19. Communication equipment & 13.00 & 13.00 & 13.00 & 13.00 & 13.00 & 1996-2001 average. \\
\hline 20. Other business fixed capital & 5.87 & 6.08 & 6.10 & 6.10 & 6.10 & 1996-2001 average. \\
\hline \multicolumn{7}{|l|}{ Expected capital gains $/ \operatorname{losses}^{4}(\Pi)$} \\
\hline 21. Computer hardware & -12.70 & -11.79 & -23.21 & -17.50 & -20.36 & See footnote 5 . \\
\hline 22. Software & 3.27 & -.56 & -.31 & -.44 & -.50 & See footnote 5 . \\
\hline 23. Communication equipment & 3.65 & -.07 & -3.01 & -4.00 & -5.75 & See footnote 6 . \\
\hline 24. Other business fixed capital & 6.31 & 2.52 & 2.55 & 2.54 & 2.53 & See footnote 5 . \\
\hline \multicolumn{7}{|l|}{ Capital-output ratios $\left(T p_{K} K / p Y\right)$} \\
\hline 25. Computer hardware & .0192 & .0293 & .0294 & .0300 & .0360 & See figure 4. \\
\hline 26. Software & .0191 & .0440 & .0618 & .0800 & .0900 & See figure 4. \\
\hline 27. Communication equipment & .0876 & .1087 & .0951 & .0875 & .1025 & See figure 4. \\
\hline 28. Other business fixed capital & 2.4227 & 2.2648 & 2.1008 & 1.9000 & 2.0500 & See figure 4. \\
\hline
\end{tabular}

Footnotes are at the end of the table. 
Table 3, continued

\begin{tabular}{|c|c|c|c|c|c|c|}
\hline \multirow[b]{2}{*}{ Parameter } & \multicolumn{3}{|c|}{ Historical Averages } & \multicolumn{2}{|c|}{ Steady-State Values } & \multirow[b]{2}{*}{$\begin{array}{l}\text { Method for Setting } \\
\text { Steady-State Values }\end{array}$} \\
\hline & $\begin{array}{l}197 \overline{4-} \\
1990\end{array}$ & $\begin{array}{l}1991- \\
1995\end{array}$ & $\begin{array}{l}1996- \\
2001\end{array}$ & $\begin{array}{l}\text { Lower } \\
\text { Bound }\end{array}$ & $\begin{array}{l}\text { Upper } \\
\text { Bound }\end{array}$ & \\
\hline \multicolumn{7}{|l|}{ Income shares ${ }^{1}(\alpha)$} \\
\hline 29. Computer hardware & .92 & 1.34 & 1.71 & 1.57 & 1.99 & Implied. See figure 5. \\
\hline 30. Software & .75 & 1.85 & 2.67 & 3.48 & 3.92 & Implied. See figure 5. \\
\hline 31. Communication equipment & 1.48 & 1.88 & 1.96 & 1.89 & 2.39 & Implied. See figure 5. \\
\hline 32. Other business fixed capital & 18.00 & 17.78 & 17.04 & 15.42 & 16.65 & Implied. See figure 5. \\
\hline 33. Other capital ${ }^{7}$ & 9.81 & 8.90 & 8.93 & 8.93 & 8.93 & 1996-2001 average. \\
\hline 34. Labor & 69.04 & 68.25 & 67.69 & 68.72 & 66.13 & Implied by lines $29-33$. \\
\hline \multicolumn{7}{|l|}{ Other parameters } \\
\hline 35. Growth of labor quality ${ }^{3}(q)$ & .32 & .65 & .38 & .30 & .30 & Assumed slower growth. \\
\hline $\begin{array}{l}\text { 36. Ratio of domestic semiconductor } \\
\text { output to domestic use }(1+\theta)\end{array}$ & .89 & .86 & 1.03 & 1.03 & 1.03 & 1996-2001 average. \\
\hline
\end{tabular}

1. Current-dollar shares, in percent.

2. Output price inflation in each sector minus that in the "other final-output" sector, in percentage points.

3. In percent.

4. Three-year moving average of price inflation for each asset, in percent.

5. Lower bound is average over 1991-2001; upper bound is midway between that value and the smaller of the 1991-1995 and 19962001 values.

6. The lower and upper bounds equal the corresponding values for the relative inflation rate of communication equipment (line 14), plus 2 percent - the assumed rate of inflation in the "other final-output" sector.

7. Includes land, inventories, and tenant-occupied housing. 


\section{Table 4}

\section{Steady-State Results}

\begin{tabular}{lcc}
\hline & $\begin{array}{c}\text { Using Lower } \\
\text { Bound Parameters }\end{array}$ & $\begin{array}{c}\text { Using Upper } \\
\text { Bound Parameters }\end{array}$ \\
\hline 1. Growth of labor productivity & & \\
& & \\
Contributions from: ${ }^{2}$ & 1.98 & \\
2. Induced capital deepening & & \\
3. $\quad$ Information technology capital & .97 & 1.47 \\
4. $\quad$ Other capital & .88 & 1.31 \\
5. Labor quality & .09 & .16 \\
6. Multifactor productivity & .30 & .30 \\
& .72 & 1.07 \\
Memo: & & 2.17 \\
7. Total IT contribution & & \\
\end{tabular}

1. In the nonfarm business sector; measured in percent.

2. Percentage points per year.

3. Equals line 3 plus the contributions included in line 6 from producers of computer hardware, software, communication equipment, and semiconductors.

Note: Detail may not sum to totals due to rounding. 


\section{Table 5}

\section{Alternative Estimates of Steady-State Growth in Labor Productivity (Percent per year)}

\begin{tabular}{|c|c|c|}
\hline & Point Estimate & Range \\
\hline 1. This paper & & 2.0 to 2.8 \\
\hline 2. Jorgenson, Ho, and Stiroh $(2002)^{1}$ & 2.25 & 1.3 to 3.0 \\
\hline 3. Congressional Budget Office $(2002)^{2}$ & 2.2 & \\
\hline 4. Economic Report of the President $(2002)^{3}$ & 2.1 & \\
\hline 5. Baily (2002) & & 2.0 to 2.5 \\
\hline 6. Gordon ${ }^{4}$ & & 2.0 to 2.2 \\
\hline 7. Kiley (2001) & & 2.6 to 3.2 \\
\hline 8. Martin $(2001)^{5}$ & 2.75 & 2.5 to 3.0 \\
\hline 9. McKinsey $(2001)^{6}$ & $\approx 2.0$ & 1.6 to 2.5 \\
\hline 10. Roberts ${ }^{7}$ & 2.6 & \\
\hline 11. DeLong (2002) & the fast-growin & \\
\hline
\end{tabular}

1. Jorgenson, Ho, and Stiroh measure productivity growth for a broader definition of the economy than do the other papers. To make their numbers comparable to those in the other studies, add 0.15 percentage point to the point estimate and range shown for Jorgenson, Ho, and Stiroh in the table.

2. Table 2-5.

3. Table 1-2, p. 55.

4. Based on personal correspondence with Robert Gordon, March 24, 2002.

5. In personal correspondence of March 23, 2002, Bill Martin indicated that his forthcoming revised estimates would be slightly lower than those in Martin (2001).

6. Chapter 3, exhibit 13.

7. Unpublished update to Roberts (2001). 
Fig. 1 - Contributions from the Use and Production of Information Technology to Growth of Labor Productivity in Nonfarm Business, 1974-2001

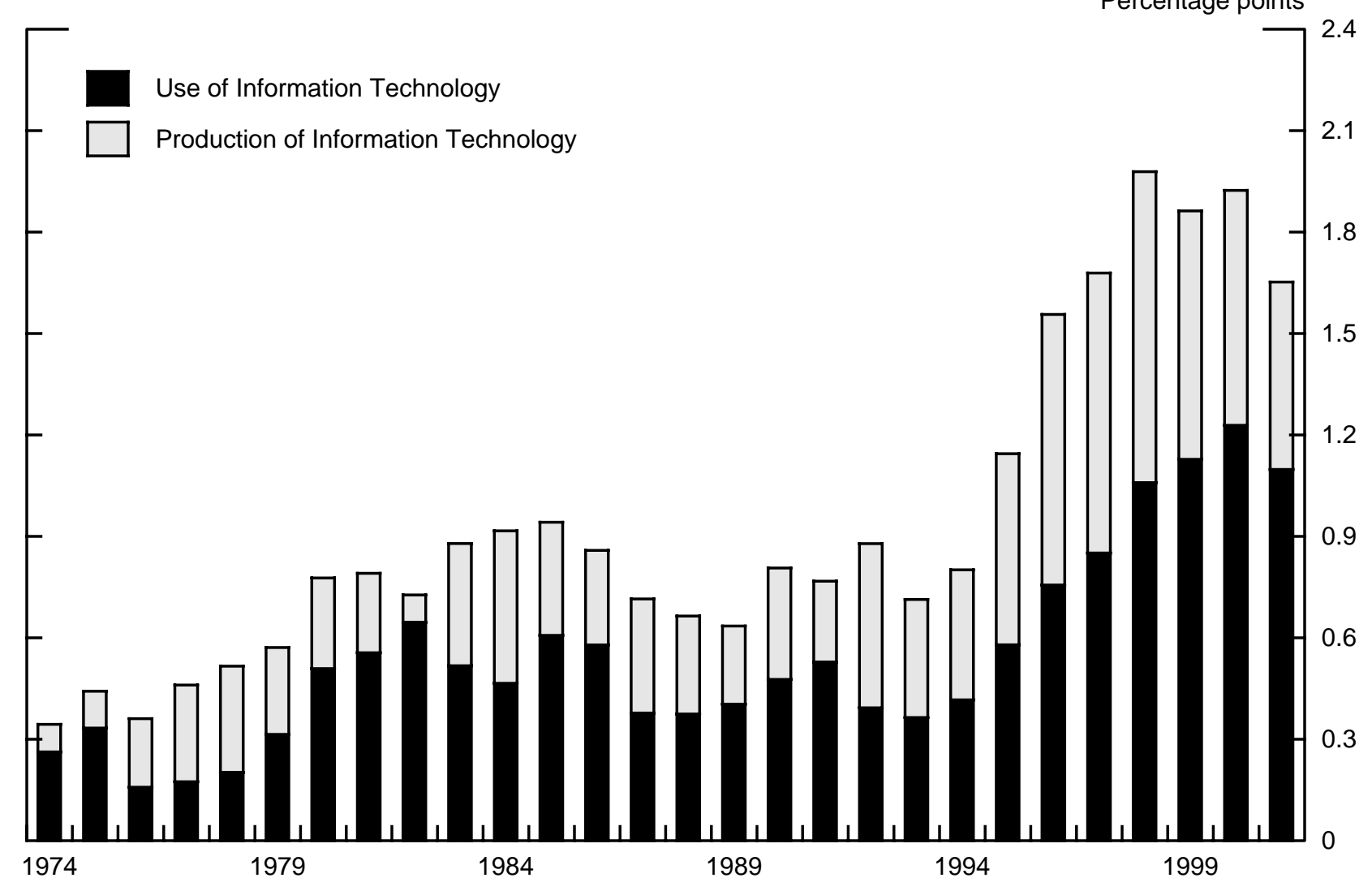




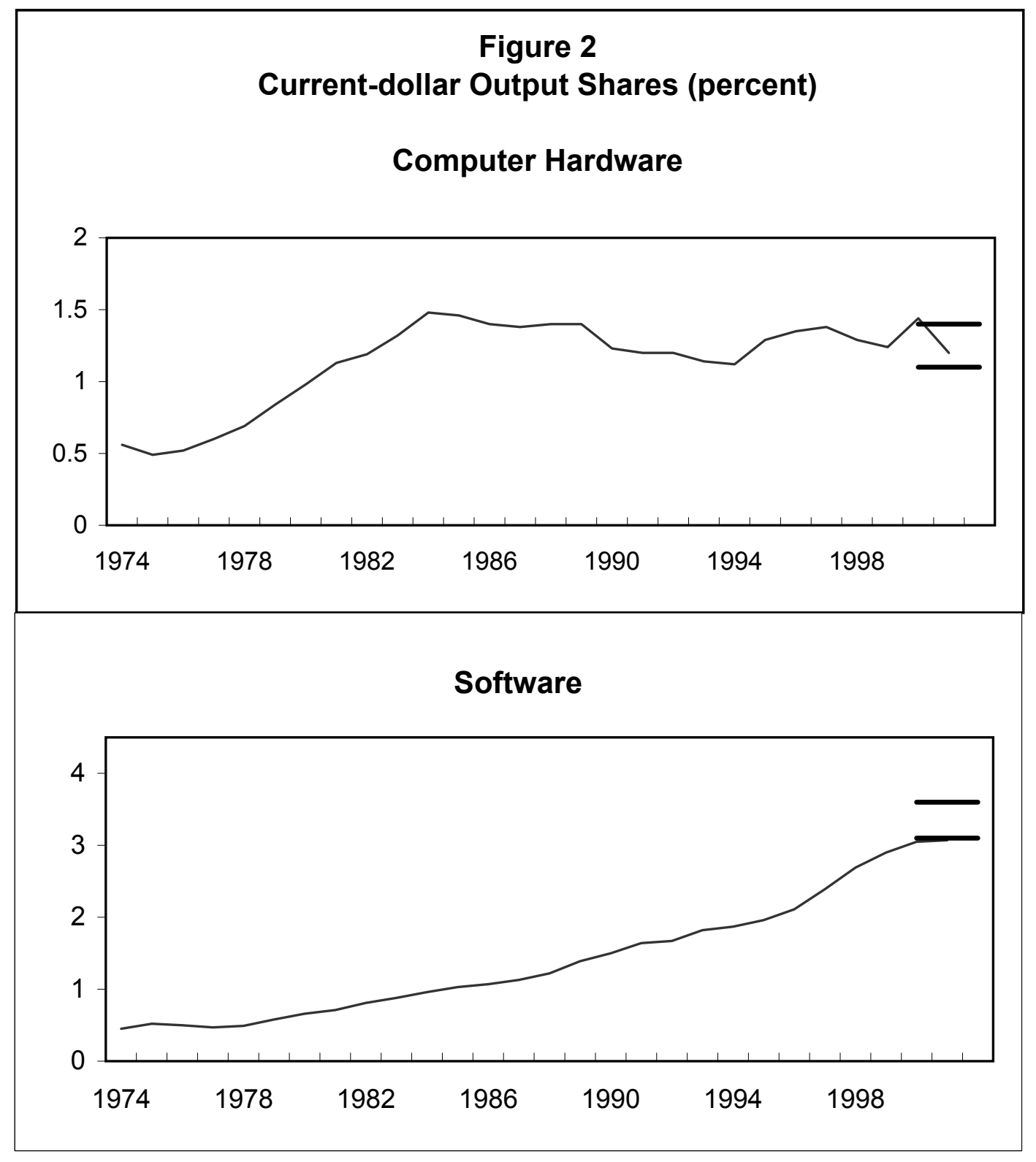




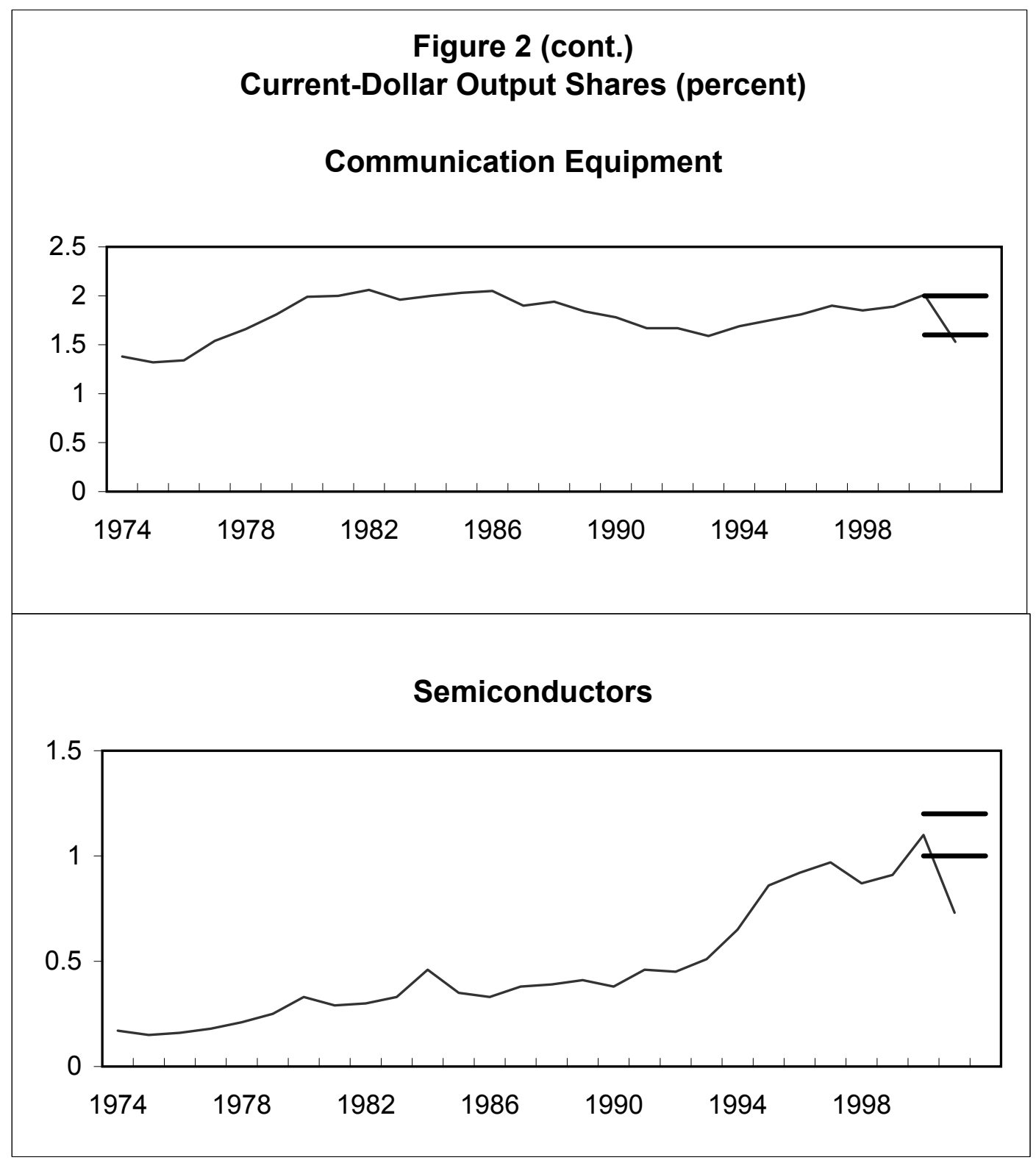




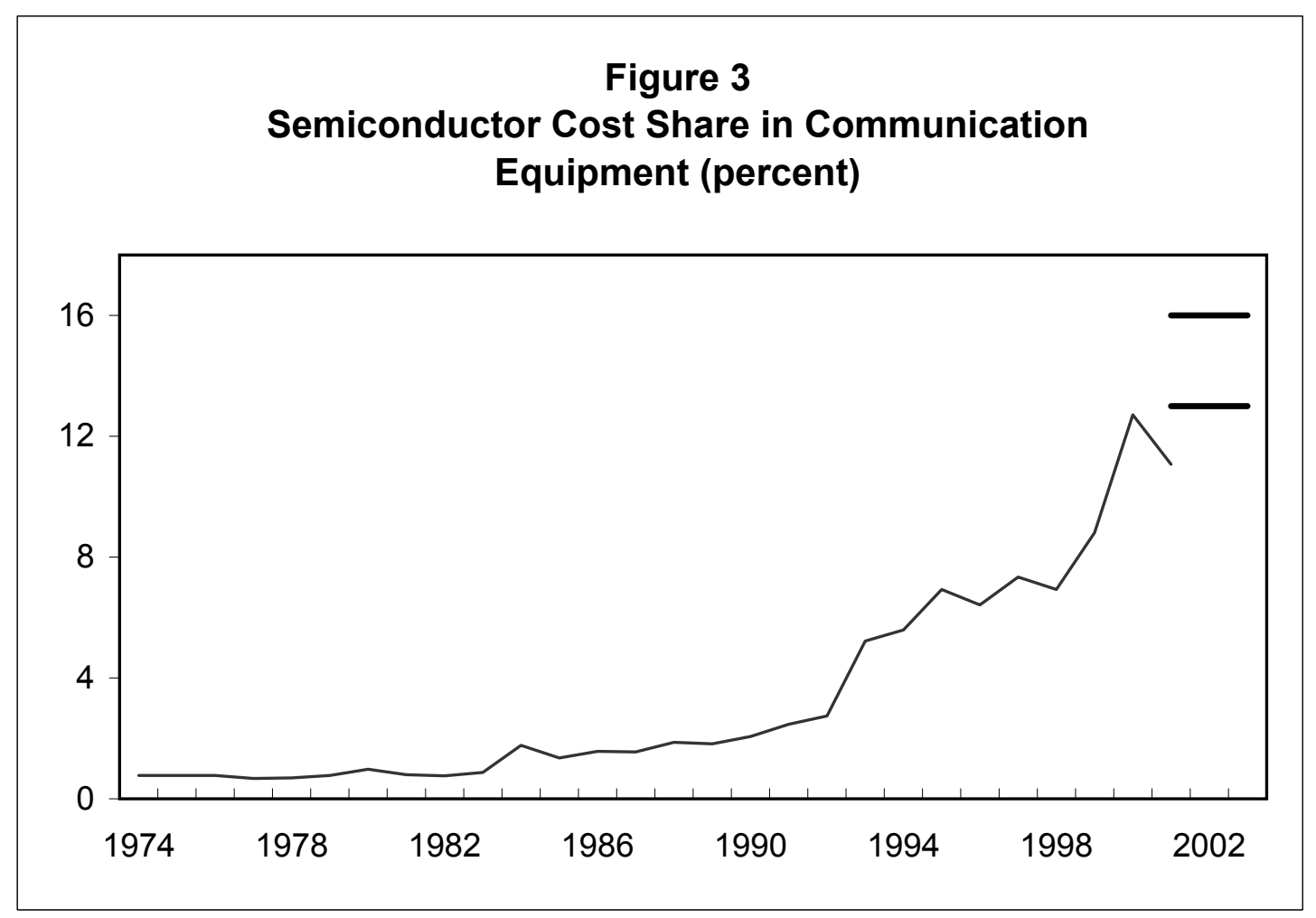




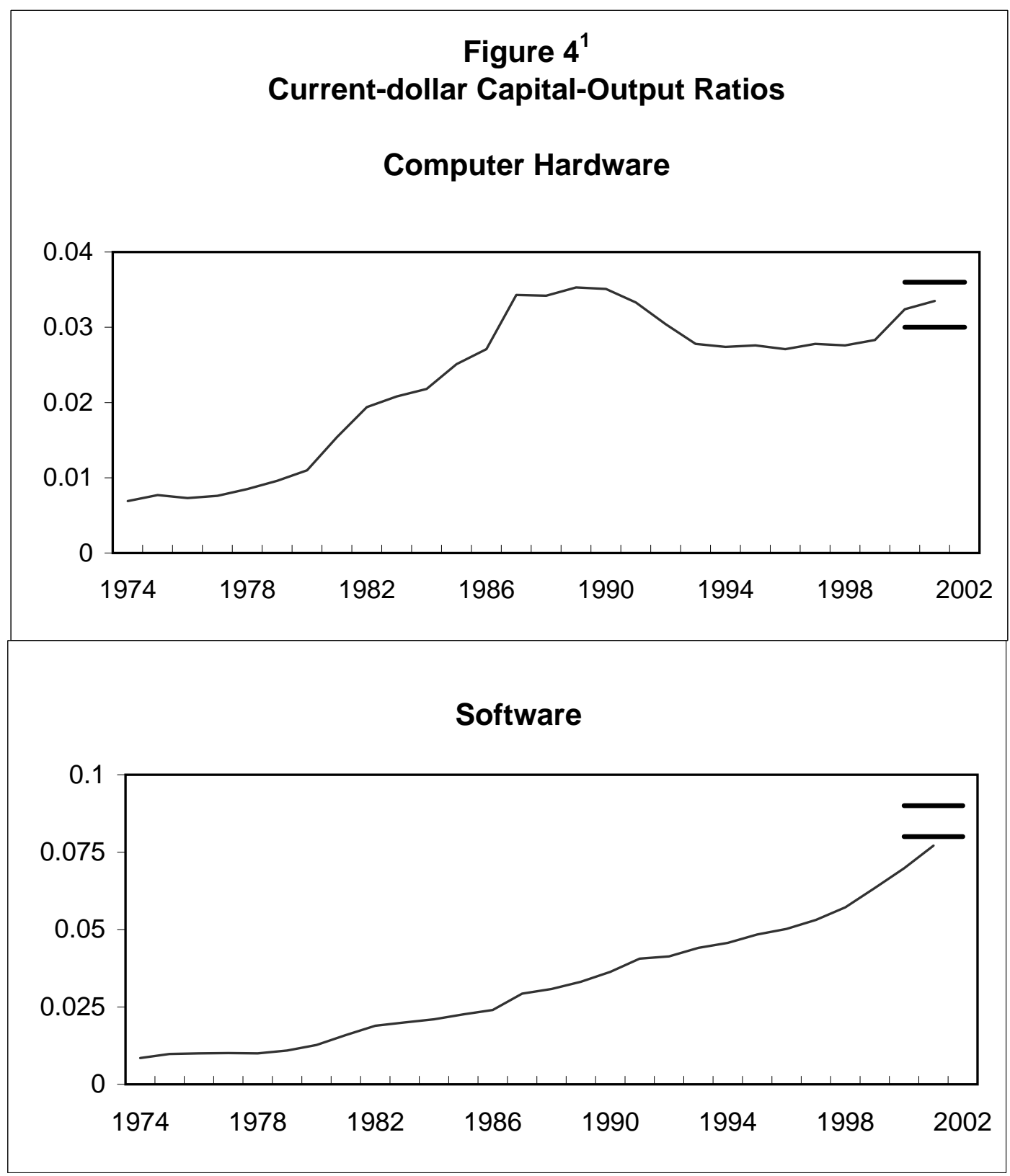

${ }^{1}$ Each subcomponent within a category is tax-weighted. 


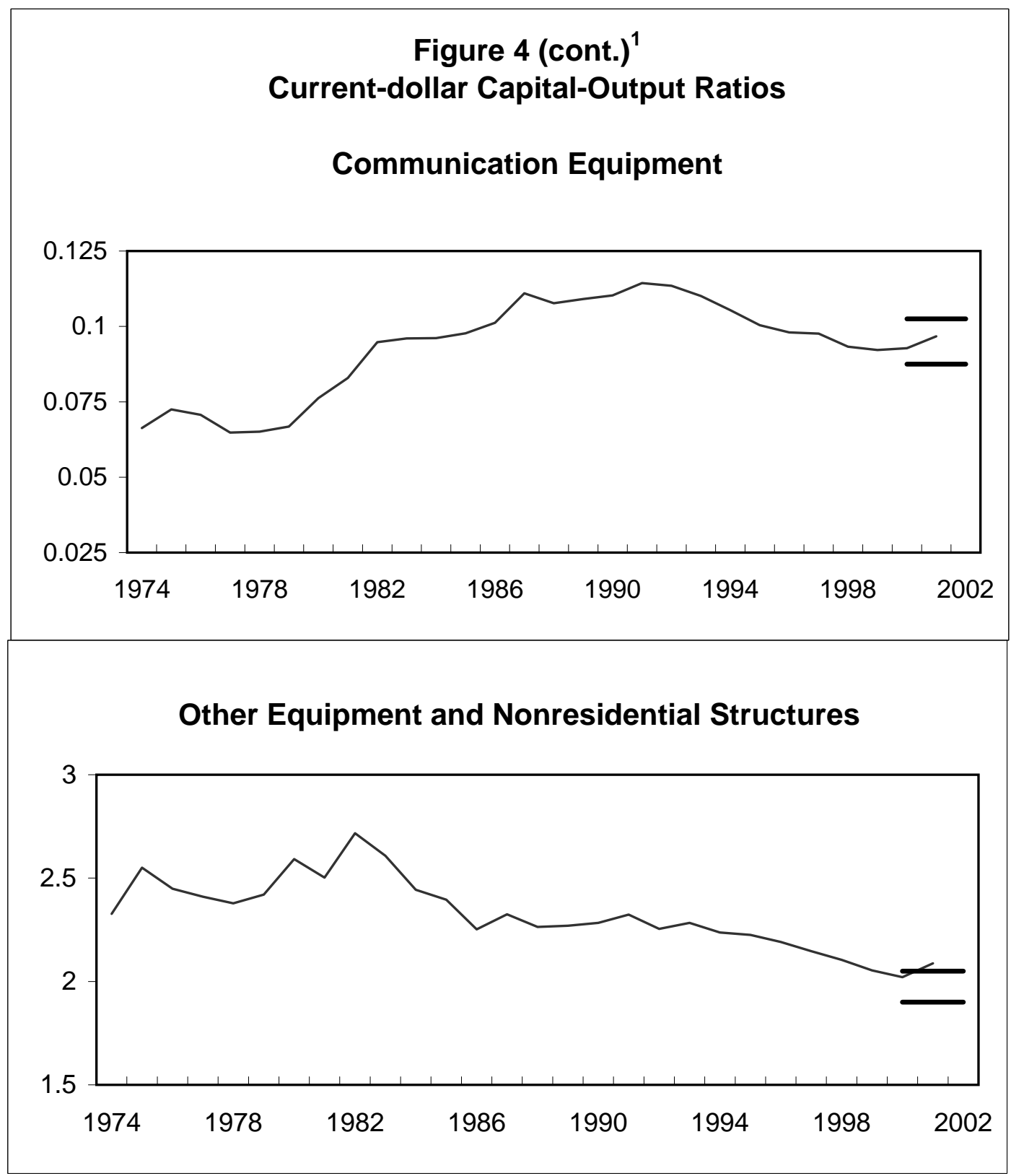

${ }^{1}$ Each subcomponent within a category is tax-weighted. 


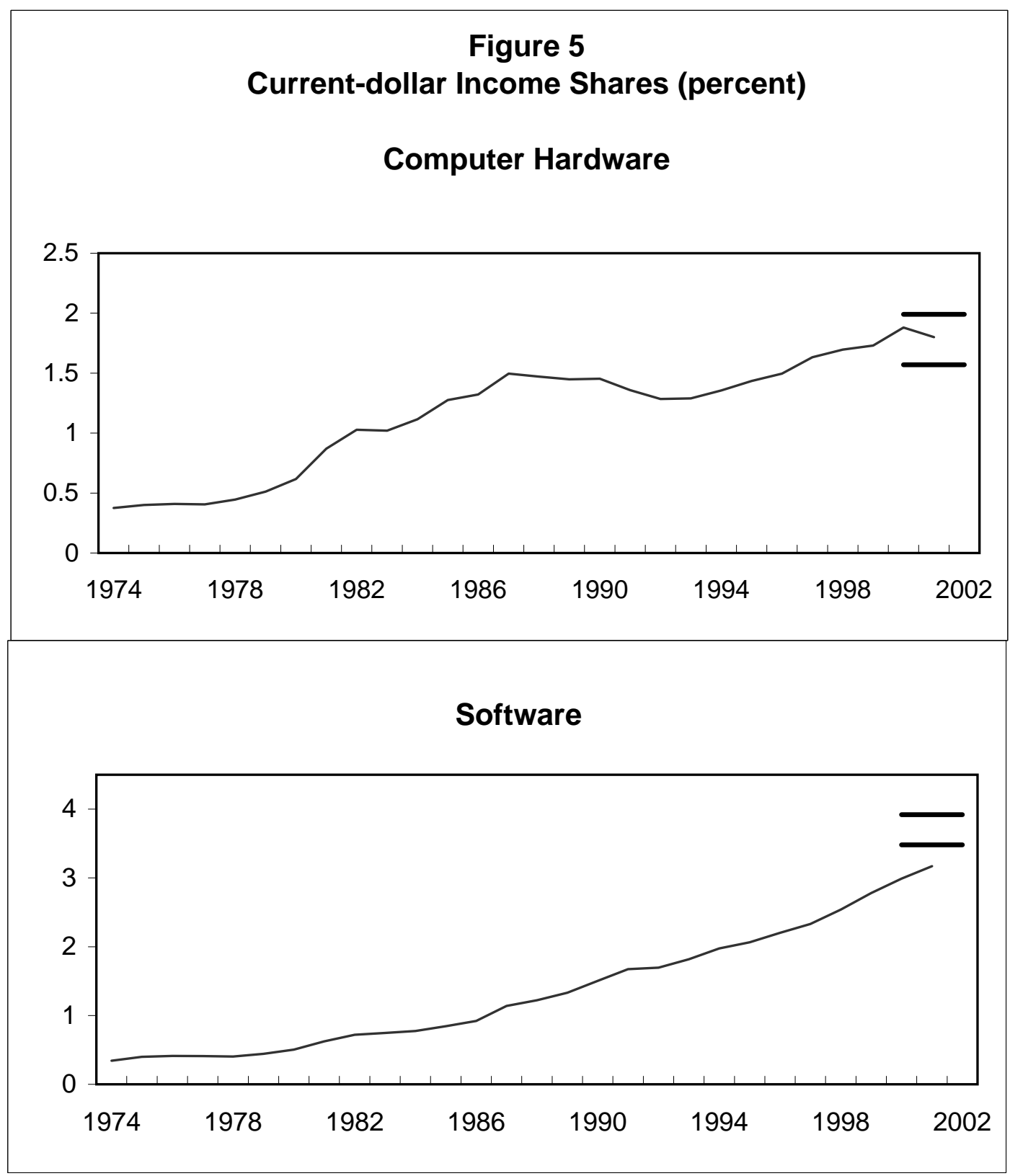




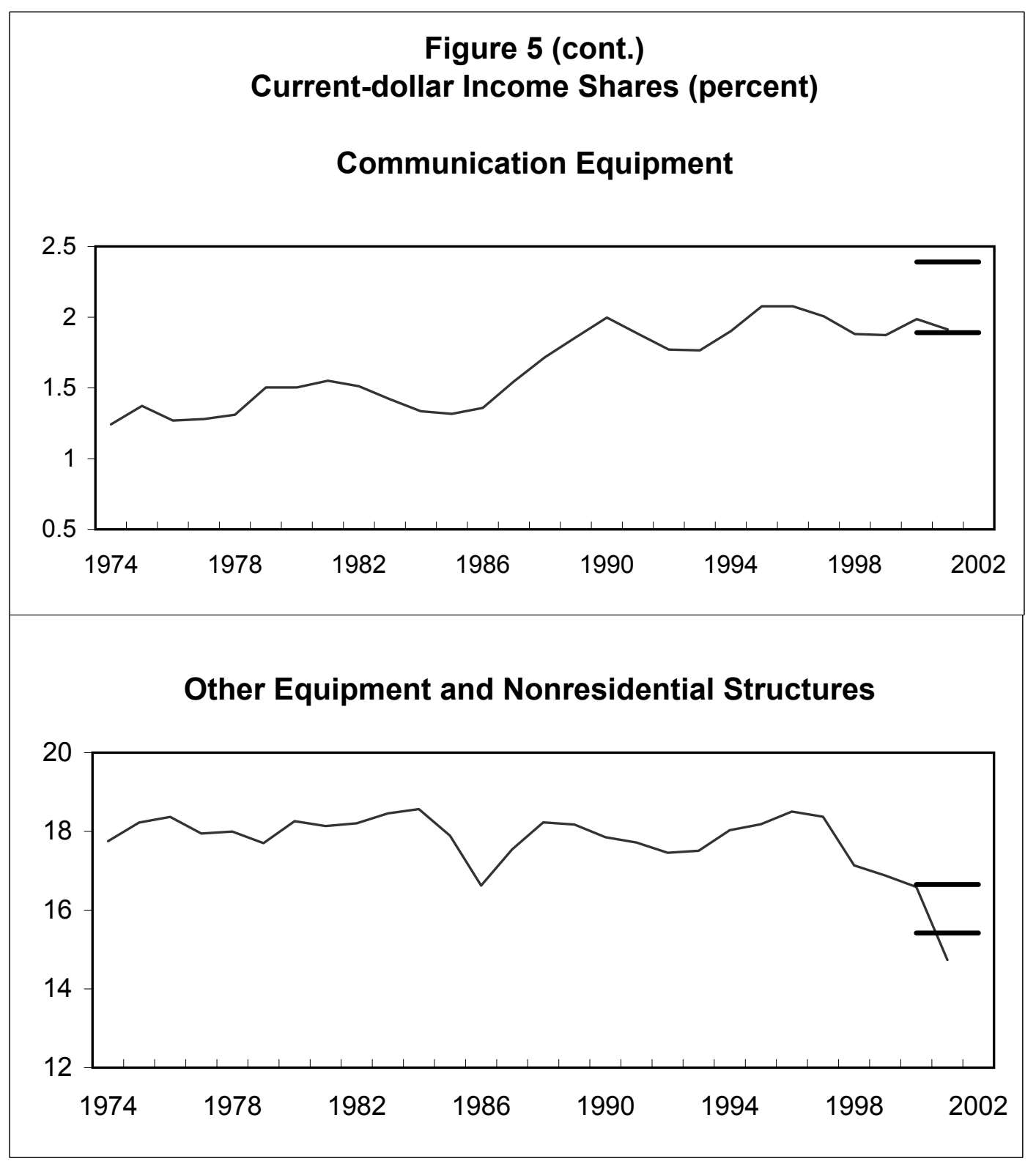




\section{APPENDIX 1: MODEL OF SECTORAL PRODUCTIVITY}

This appendix presents our model of sectoral productivity and derives key results for our analysis of growth in aggregate labor productivity. The model divides nonfarm business into five sectors. Four of the sectors produce final output (computer hardware, software, communication equipment, and all other final output). The fifth sector produces semiconductors, which are either consumed as an intermediate input by the final-output sectors or exported to foreign firms. To focus on essential linkages, the model abstracts from all intermediate inputs besides semiconductors.

\section{The Model}

Let $Y_{i}(i=1, \ldots, 4)$ denote the production of the final-output sectors. Each sector produces investment goods $\left(I_{i}\right)$ and consumption goods $\left(C_{i}\right)$ for domestic use, where $I_{i}$ and $C_{i}$ are identical goods sold to different agents (firms buy $I_{i}$, while households buy $C_{i}$ ). Let $I_{i, j}$ and $I_{i, s}$ denote, respectively, the purchases of $I_{i}$ by final-output sector $j(j=1, \ldots, 4)$ and by semiconductor producers, with $I_{i}=\sum_{j} I_{i, j}+I_{i, s}$. Each sector also produces goods for export $\left(X_{i}\right)$. To produce this output, sector $i$ employs labor $\left(L_{i}\right)$ and various types of capital $\left(K_{j, i}, j=1, \ldots, 4\right)$, and it purchases semiconductors $\left(S_{i}\right)$ as an intermediate input. With this notation, the production function for each final-output sector can be written as (1) $Y_{i}=C_{i}+\sum_{i=1}^{4} I_{i, j}+I_{i, s}+X_{i}=F_{i}\left(L_{i}, K_{1, i}, K_{2, i}, K_{3, i}, K_{4, i}, S_{i}, z_{i}\right)$ for $i=1, \ldots, 4$, where $z_{i}$ measures the level of multifactor productivity. Although we do not explicitly model foreign production, the capital stocks $K_{j, i}$ should be regarded as including

\footnotetext{
${ }^{1}$ When either $I$ or $K$ has a double subscript, the first subscript indicates the sector that produced the investment good, while the second subscript indicates the sector that uses it as an input to production.
} 
imported capital goods of type $j$. To ease the notational burden, we have suppressed time subscripts in equation 1 and will do so throughout this appendix.

The output of the semiconductor sector $\left(Y_{S}\right)$ is either sold as intermediate input to the domestic final-output sectors $\left(S_{d}\right)$ or is exported $\left(S_{x}\right)$. The semiconductors purchased by the domestic final-demand sectors $\left(S_{i}\right)$ include imported semiconductors $\left(S_{m}\right)$, which implies that the production sold for domestic use can be written as $S_{d}=\sum_{i} S_{i}-S_{m}$. We assume that semiconductor producers employ labor and the same set of capital inputs as the final-output sectors. With these assumptions,

$$
Y_{s}=S_{d}+S_{x}=\sum_{i=1}^{4} S_{i}+S_{x}-S_{m}=F_{s}\left(L_{s}, K_{1, s}, K_{2, s}, K_{3, s}, K_{4, s}, z_{s}\right) .
$$

The next step is to define the relationship between the sectoral variables and their aggregate counterparts. Following the guidance of index number theory, we express the growth in aggregate final output as a superlative index of growth in sectoral final output.

Let $\dot{Z} \equiv(\partial Z / \partial t) / Z$ denote the growth in any variable $Z$. Then, the growth of aggregate nonfarm business output $(Y)$ in our model is

$$
\dot{Y}=\sum_{i=1}^{4} \mu_{i} \dot{Y}_{i}+\mu_{S, x} \dot{S}_{x}-\mu_{S, m} \dot{S}_{m}
$$

where $\mu_{i} \equiv p_{i} Y_{i} / p Y$ (for $\left.i=1, \ldots, 4\right), \mu_{S, x} \equiv p_{s} S_{x} / p Y, \mu_{S, m} \equiv p_{s} S_{m} / p Y$, and $p Y \equiv \sum_{i=1}^{4} p_{i} Y_{i}+p_{s} S_{x}-p_{s} S_{m}{ }^{2} p_{i}$ and $p_{s}$ denote the prices of final output and semiconductors, respectively, and $p Y$ represents aggregate current-dollar output.

\footnotetext{
${ }^{2}$ Equation 3 is just one of several possible superlative indexes of output growth. It differs slightly from the Fisher chain index used in the U.S. National Income and Product Accounts.
} 
Equation 3 expresses the growth in aggregate output as a share-weighted average of sectoral output growth, where the shares are in current dollars. Note that the semiconductors sold to domestic final-output sectors are an intermediate input for those sectors and thus do not appear in equation 3; only net exports of semiconductors enter the equation, consistent with the treatment of semiconductors in the National Income and Product Accounts.

The definition of labor and capital aggregates in our model is very simple. We assume that labor input used in a given sector is identical to that used in any other sector. We also impose this assumption on each type of capital. Given these assumptions, we can directly aggregate the sectoral inputs, without the need for superlative aggregation formulas. That is,

(4) $\quad L=\sum_{i=1}^{4} L_{i}+L_{S}$

(5) $\quad K_{j}=\sum_{i=1}^{4} K_{j, i}+K_{j, s} \quad$ for $j=1, \ldots, 4$.

Moreover, with this setup, there is a common wage rate (w) for labor in every sector and, likewise, a common rental rate $\left(r_{j}\right)$ for all capital of type $j$.

Labor input in each sector is the product of hours worked $\left(H_{i}\right)$ and labor quality $\left(q_{i}\right)$, where quality reflects the characteristics of the workers employed in that sector. We allow labor quality to change over time, but given our assumption of identical labor input across sectors, $q_{i}$ must equal a common value $q$ in every sector at a given point in time. Using equation 4 , this implies that 
(6)

$$
L=\sum_{i=1}^{4} q H_{i}+q H_{S}=q H
$$

where $H$ represents aggregate hours worked.

To derive the growth-accounting equation for each sector, we impose the standard neoclassical assumptions of perfect competition and constant returns to scale. We also assume that there are no adjustment costs. Under these assumptions, profit-maximizing firms will set the marginal revenue product of each input equal to its one-period cost:

$$
\begin{aligned}
& w=p_{s}\left(\partial F_{s} / \partial L_{s}\right)=p_{i}\left(\partial F_{i} / \partial L_{i}\right) \text { for } i=1, \ldots, 4 \\
& r_{j}=p_{s}\left(\partial F_{s} / \partial K_{j, s}\right)=p_{i}\left(\partial F_{i} / \partial K_{j, i}\right) \text { for } i, j=1, \ldots, 4 \\
& p_{s}=p_{i}\left(\partial F_{i} / \partial S_{i}\right) \text { for } i=1, \ldots, 4 .
\end{aligned}
$$

If we totally differentiate equations 1 and 2 and then impose conditions 7 through 9 , we obtain the standard growth-accounting equations:

$$
\begin{aligned}
& \dot{Y}_{i}=\beta_{i}^{L} \dot{L}_{i}+\sum_{j=1}^{4} \beta_{j, i}^{K} \dot{K}_{j, i}+\beta_{i}^{S} \dot{S}_{i}+\dot{M F P_{i}} \text { for } i=1, \ldots, 4 \\
& \dot{Y}_{S}=\gamma^{L} \dot{L}_{S}+\sum_{j=1}^{4} \gamma_{j}^{K} \dot{K_{j, S}}+\dot{M F} P_{S}
\end{aligned}
$$

where $\dot{M} \dot{F P}_{i} \equiv\left(\partial F_{i} / \partial z_{i}\right) / F_{i}, \dot{M F P_{S}} \equiv\left(\partial F_{S} / \partial z_{s}\right) / F_{S}$, and the $\beta$ 's and $\gamma$ 's represent the

following income shares: $\beta_{i}^{L} \equiv w L_{i} / p_{i} Y_{i}$, the labor share in sector $i ; \beta_{j, i}^{K} \equiv r_{j} K_{j, i} / p_{i} Y_{i}$, the share for capital of type $j$ in sector $i ; \beta_{i}^{S} \equiv p_{s} S_{i} / p_{i} Y_{i}$, the semiconductor share in sector $i$; $\gamma^{L} \equiv w L_{s} / p_{s} Y_{s}$, the labor share in the semiconductor sector; and $\gamma_{j}^{K} \equiv r_{j} K_{j, s} / p_{s} Y_{s}$, the share for capital of type $j$ in the semiconductor sector. Given the assumption of constant returns, the income shares in each sector sum to one. 


\section{Aggregate Labor Productivity}

Proposition 1 derives the expression for growth in aggregate labor productivity in our model.

\section{Proposition 1}

Assume that all markets are perfectly competitive, that production exhibits constant returns to scale in every sector, and that input use is not subject to adjustment costs.

Then, in the model described by equations 1 through 11, the growth-accounting equation for aggregate labor productivity is

$$
\dot{Y}-\dot{H}=\sum_{j=1}^{4} \alpha_{j}^{K}\left(\dot{K}_{j}-\dot{H}\right)+\alpha^{L} \dot{q}+\dot{M F P},
$$

where

$$
\dot{M F P}=\sum_{i=1}^{4} \mu_{i} \dot{M F P}{ }_{i}+\mu_{S} \dot{M F P}
$$

and $\alpha^{L}=w L / p Y ; \alpha_{j}^{K}=r_{j} K_{j} / p Y ; \mu_{i}=p_{i} Y_{i} / p Y$; and $\mu_{S}=p_{S} Y_{s} / p Y$.

Proof.

To begin, substitute the expression for $\dot{Y}_{i}$ from equation 10 into equation 3 :

$$
\begin{aligned}
\dot{Y}= & \sum_{i=1}^{4} \mu_{i}\left[\beta_{i}^{L} \dot{L}_{i}+\sum_{j=1}^{4} \beta_{j, i}^{K} \dot{K}_{j, i}+\beta_{i}^{S} \dot{S}_{i}+\dot{M F P_{i}}\right]+\mu_{S, x} \dot{S}_{x}-\mu_{S, m} \dot{S}_{m} \\
= & \sum_{i=1}^{4} \alpha^{L}\left(L_{i} / L\right) \dot{L}_{i}+\sum_{j=1}^{4} \sum_{i=1}^{4} \alpha_{j}^{K}\left(K_{j, i} / K_{j}\right) \dot{K}_{j, i}+\sum_{i=1}^{4} \mu_{S}\left(S_{i} / Y_{S}\right) \dot{S}_{i} \\
& +\sum_{i=1}^{4} \mu_{i} \dot{M F P}_{i}+\mu_{S, x} \dot{S}_{x}-\mu_{S, m} \dot{S}_{m}
\end{aligned}
$$

where the second equality follows (after some algebra) from the definitions of the $\alpha$ 's, 
$\beta$ 's, and $\mu$ 's. Next, totally differentiate equation 2 to obtain

$$
\dot{Y}_{S}=\sum_{i=1}^{4}\left(S_{i} / Y_{S}\right) \dot{S}_{i}+\left(S_{x} / Y_{S}\right) \dot{S}_{x}-\left(S_{m} / Y_{S}\right) \dot{S_{m}}
$$

Multiplying equation 13 by $\mu_{S}$ and using the definitions of $\mu_{S}, \mu_{S, x}$, and $\mu_{S, m}$,

$$
\sum_{i=1}^{4} \mu_{S}\left(S_{i} / Y_{S}\right) \dot{S}_{i}=\mu_{S} \dot{Y}_{S}-\mu_{S, x} \dot{S}_{x}+\mu_{S, m} \dot{S}_{m}
$$

Now, substitute equation 14 into equation 12, which yields

$$
\dot{Y}=\alpha^{L} \sum_{i=1}^{4}\left(L_{i} / L\right) \dot{L}_{i}+\sum_{j=1}^{4} \alpha_{j}^{K} \sum_{i=1}^{4}\left(K_{j, i} / K_{j}\right) \dot{K_{j, i}}+\sum_{i=1}^{4} \mu_{i} \dot{M F P_{i}}+\mu_{S} \dot{Y}_{S} .
$$

Next, totally differentiate equations 4 and 5 :

$$
\begin{aligned}
& \dot{L}=\sum_{i=1}^{4}\left(L_{i} / L\right) \dot{L}_{i}+\left(L_{S} / L\right) \dot{L}_{S} \\
& \dot{K}_{j}=\sum_{i=1}^{4}\left(K_{j, i} / K_{j}\right) \dot{K}_{j, i}+\left(K_{j, S} / K_{j}\right) \dot{K}_{j, S},
\end{aligned}
$$

and substitute these equations into 15 :

$$
\begin{aligned}
& \dot{Y}= \alpha^{L}\left[\dot{L}-\left(L_{S} / L\right) \dot{L}_{S}\right]+\sum_{j=1}^{4} \alpha_{j}^{K}\left[\dot{K}_{j}-\left(K_{j, S} / K_{j}\right) \dot{K_{j, S}}\right]+\sum_{i=1}^{4} \mu_{i} \dot{M F P_{i}}+\mu_{S} \dot{Y}_{S} \\
&=\alpha^{L} \dot{L}+\sum_{j=1}^{4} \alpha_{j}^{K} \dot{K}_{j}+\sum_{i=1}^{4} \mu_{i} \dot{M F P_{i}} \\
&+\mu_{S}\left[\dot{Y}_{S}-\left(\alpha^{L} / \mu_{S}\right)\left(L_{S} / L\right) \dot{L_{S}}-\sum_{j=1}^{4}\left(\alpha_{j}^{K} / \mu_{S}\right)\left(K_{j, S} / K_{j}\right) \dot{K_{j, S}}\right] \\
&=\alpha^{L} \dot{L}+\sum_{j=1}^{4} \alpha_{j}^{K} \dot{K}_{j}+\sum_{i=1}^{4} \mu_{i} \dot{M F P_{i}}+\mu_{S}\left[\dot{Y}_{S}-\gamma^{L} \dot{L}_{S}-\sum_{j=1}^{4} \gamma_{j}^{K} \dot{K_{j, S}}\right] \\
&=\alpha^{L} \dot{L}+\sum_{j=1}^{4} \alpha_{j}^{K} \dot{K}_{j}+\sum_{i=1}^{4} \mu_{i} \dot{M F P_{i}}+\mu_{S} \dot{M F P_{S}},
\end{aligned}
$$


where the third equality follows from the definitions of the $\alpha$ 's, $\gamma^{\prime}$ s, and $\mu$ 's, and the fourth equality follows from equation 11. To complete the proof, recall that $\dot{L}=\dot{H}+\dot{q}$ from equation 6 and that the $\alpha$ 's sum to one under constant returns to scale. Hence,

$$
\alpha^{L} \dot{L}=\alpha^{L}(\dot{H}+\dot{q})=\dot{H}-\sum_{j=1}^{4} \alpha_{j}^{K} \dot{H}+\alpha^{L} \dot{q}
$$

Substitute equation 19 into 18 , which produces

$$
\dot{Y}-\dot{H}=\sum_{j=1}^{4} \alpha_{j}^{K}\left(\dot{K}_{j}-\dot{H}\right)+\alpha^{L} \dot{q}+\sum_{i=1}^{4} \mu_{i} \dot{M F P_{i}}+\mu_{S} \dot{M F P_{S}} .
$$

\section{More on Aggregate MFP}

Proposition 1 showed that aggregate MFP growth in our model equals a shareweighted sum of MFP growth in each sector. This result can be rewritten to highlight the input-output connections between semiconductor producers and the final-output sectors. In effect, we can integrate semiconductor producers with the final-output sectors that they supply.

\section{Proposition 2}

Under the assumptions of Proposition 1,

$$
\dot{M F P}=\sum_{i=1}^{4} \mu_{i} \dot{M F P_{i}}+\mu_{S} \dot{M F P_{S}}=\sum_{i=1}^{4} \mu_{i}\left[\dot{M F P_{i}}+\beta_{i}^{S}(1+\theta) \dot{M F P_{S}}\right],
$$

where $1+\theta=Y_{S} / \sum_{i=1}^{4} S_{i}$, the ratio of domestic semiconductor output to domestic use of semiconductors. 


\section{Proof.}

Using equation 2 and recalling the definitions of $\mu_{i}, \beta_{i}^{S}, \mu_{S, x}$, and $\mu_{S, m}$,

$$
\begin{aligned}
\mu_{S} & \equiv p_{S} Y_{S} / p Y=p_{S}\left[\sum_{i=1}^{4} S_{i}+S_{x}-S_{m}\right] / p Y \\
& =\sum_{i=1}^{4}\left(p_{i} Y_{i} / p Y\right)\left(p_{S} S_{i} / p_{i} Y_{i}\right)+p_{S}\left(S_{x}-S_{m}\right) / p Y=\sum_{i=1}^{4} \mu_{i} \beta_{i}^{S}+\mu_{S, x}-\mu_{S, m} .
\end{aligned}
$$

Note that $\mu_{S, x}-\mu_{S, m}$ can be written as $\mu_{S}\left(S_{x}-S_{m}\right) / Y_{S}$, so that equation 21 becomes

$$
\mu_{S}=\sum_{i=1}^{4} \mu_{i} \beta_{i}^{S} /\left[1-\left(S_{x}-S_{m}\right) / Y_{S}\right]=\sum_{i=1}^{4} \mu_{i} \beta_{i}^{S} /\left[\sum_{i=1}^{4} S_{i} / Y_{S}\right]=\sum_{i=1}^{4} \mu_{i} \beta_{i}^{S}(1+\theta),
$$

where the second equality follows from equation 2 and the third from the definition $1+\theta \equiv Y_{S} / \sum_{i=1}^{4} S_{i}$. Finally, substitute equation 22 into the expression from Proposition

1 for growth in aggregate $M F P$ :

$$
\dot{M F P}=\sum_{i=1}^{4} \mu_{i} \dot{M F P_{i}}+\mu_{S} \dot{M F P_{S}}=\sum_{i=1}^{4} \mu_{i}\left[\dot{M F} P_{i}+\beta_{i}^{S}(1+\theta) \dot{M F} P_{S}\right] .
$$

\section{Measuring Sectoral MFP}

To make use of propositions 1 and 2, we need to estimate MFP growth in each sector. This can be done either from the sectoral production functions, as in equations 10 and 11, or from the sectoral cost functions - the "dual" approach. We opt for the dual approach because the required data are more readily available. The dual counterparts to equations 10 and 11 are:

$$
\dot{p}_{i}=\beta_{i}^{L} \dot{w}+\sum_{j=1}^{4} \beta_{j, i}^{K} \dot{r}_{j}+\beta_{i}^{S} \dot{p}_{S}-\dot{M F P_{i}} \quad \text { for } i=1, \ldots, 4
$$




$$
\dot{p}_{S}=\gamma^{L} \dot{w}+\sum_{j=1}^{4} \gamma_{j}^{K} \dot{r}_{j}-\dot{M F P}_{S}
$$

These equations state that the growth in each sector's output price equals the growth in the share-weighted average of its input costs, minus the growth in MFP. MFP growth enters with a negative sign because efficiency gains hold down a sector's output price given its input costs.

To reduce the amount of data needed to estimate MFP growth from equations 24 and 25 , we assume that every sector has the same labor and capital shares up to a scaling factor that reflects the intensity of semiconductor use. That is,

$$
\frac{\beta_{1}^{L}}{1-\beta_{1}^{S}}=\ldots=\frac{\beta_{4}^{L}}{1-\beta_{4}^{S}}=\gamma^{L} \text { and } \frac{\beta_{j, 1}^{K}}{1-\beta_{1}^{S}}=\ldots=\frac{\beta_{j, 4}^{K}}{1-\beta_{4}^{S}}=\gamma_{j}^{K} \text { for } j=1, \ldots, 4
$$

One can easily verify that the restricted factor shares sum to one in each sector. Also, given equation 26, one can show (with some algebra) that $\gamma^{L}=\alpha^{L}$ and $\gamma_{j}^{K}=\alpha_{j}^{K}$ - that is, the income shares for aggregate nonfarm business equal their counterparts in the semiconductor sector. Substituting equation 26 into 24 and making use of the correspondence between the $\gamma$ 's and the $\alpha$ 's, we obtain

$$
\dot{p}_{i}=\left(1-\beta_{i}^{S}\right)\left[\alpha^{L} \dot{w}+\sum_{j=1}^{4} \alpha_{j}^{K} \dot{r}_{j}\right]+\beta_{i}^{S} \dot{p}_{S}-\dot{M F P} P_{i} \quad \text { for } i=1, \ldots 4
$$

Let $\dot{V} \equiv\left(\alpha^{L} \dot{w}+\sum_{j=1}^{4} \alpha_{j}^{K} \dot{r_{j}}\right)$ denote the share-weighted growth in labor and capital costs for the nonfarm business sector as a whole. Substitute $\dot{V}$ into the dual equations 25 and 27, noting that $\gamma^{L}=\alpha^{L}$ and $\gamma_{j}^{K}=\alpha_{j}^{K}$ in equation 25. The result is:

$$
\dot{p}_{i}=\left(1-\beta_{i}^{S}\right) \dot{V}+\beta_{i}^{S} \dot{p}_{S}-\dot{M F P} P_{i} \quad \text { for } i=1, \ldots, 3
$$




$$
\dot{p}_{4}=\left(1-\beta_{4}^{S}\right) \dot{V}+\beta_{4}^{S} \dot{p}_{S}-\dot{M F P}{ }_{4}
$$

$$
\dot{p}_{S}=\dot{V}-\dot{M F} P_{S}
$$

where we have specifically identified sector 4 , which will serve as the numeraire sector.

We now use the dual equations to derive expressions for MFP growth in two cases. In the first case, we infer the rates of sectoral MFP growth that are consistent with an independent estimate of aggregate MFP growth (from the Bureau of Labor Statistics). This case represents the methodology we use to compute growth contributions through 2001. In the second case, which we use for our steady-state analysis, we solve for aggregate MFP growth and MFP growth in sectors 1 through 3, conditional on an assumed pace of MFP growth in sector 4. The next proposition derives the expressions for sectoral MFP growth in both cases.

\section{Proposition 3}

Let $\pi_{S} \equiv \dot{p}_{S}-\dot{p}_{4}$ and $\pi_{i} \equiv \dot{p}_{i}-\dot{p}_{4}(i=1, \ldots, 3)$ denote the rate of change in each sector's output price relative to that in sector 4 . Given the dual equations $28-30$, the solutions for sectoral and aggregate MFP growth are as follows.

Case I: Conditioning on Aggregate MFP Growth

$$
\begin{aligned}
& \dot{M F P_{4}}=\left(1-\beta_{4}^{S}\right)\left(\dot{M F P}+\sum_{i=1}^{3} \mu_{i} \pi_{i}\right)+\left[\beta_{4}^{S}+\left(1-\beta_{4}^{S}\right)\left(1-\sum_{i=1}^{4} \mu_{i}\right)\right] \pi_{S} \\
& \dot{M} P_{S}=\left(\dot{M F P_{4}}-\pi_{S}\right) /\left(1-\beta_{4}^{S}\right) \\
& \dot{M F P_{i}}=\dot{M} \dot{F} P_{4}-\pi_{i}-\left(\beta_{i}^{S}-\beta_{4}^{S}\right) \dot{M F P} P_{S} \quad \text { for } i=1, \ldots, 3
\end{aligned}
$$




\section{Case II: Conditioning on MFP Growth in Sector 4}

$$
\begin{aligned}
& \dot{M F P_{S}}=\left(\dot{M F P_{4}}-\pi_{S}\right) /\left(1-\beta_{4}^{S}\right) \\
& \dot{M F P_{i}}=\dot{M F P_{4}}-\pi_{i}-\left(\beta_{i}^{S}-\beta_{4}^{S}\right) \dot{M F P_{S}} \quad \text { for } i=1, \ldots, 3 \\
& \dot{M F P}=\sum_{i=1}^{4} \dot{\mu}_{i} \dot{M F P_{i}}+\mu_{S} \dot{M F P_{S}}
\end{aligned}
$$

\section{Proof.}

The proof for case II is nearly immediate. Subtract equation 29 from equations 28

and 30. After rearranging terms and using equation 30 to substitute $\dot{M F P_{S}}$ for $\dot{V}-\dot{p_{S}}$, we obtain:

$$
\begin{aligned}
\dot{M F P} & =\dot{M F P_{4}}-\pi_{i}-\left(\beta_{i}^{S}-\beta_{4}^{S}\right) \dot{M F P_{S}} \text { for } i=1, \ldots, 3 \\
\dot{M F P}_{S} & =\left(\dot{M F P_{4}}-\pi_{S}\right) /\left(1-\beta_{4}^{S}\right) .
\end{aligned}
$$

Equations 31 and 32, plus the expression for $\dot{M F P}$ derived in proposition 1, establish the results for case II. Note that the solution is recursive - first solve for $M \dot{F} P_{S}$ from equation 32 , then substitute the result into equation 31 , and finally substitute all the sectoral MFP growth rates into the expression for aggregate MFP growth.

To prove the result for case I, substitute equations 31 and 32 into the expression for aggregate MFP growth. After rearranging terms, this yields:

$$
\dot{M F P}=\sum_{i=1}^{4} \mu_{i} \dot{M F P}+\mu_{S} \dot{M F P}
$$




$$
\begin{aligned}
=\left[\sum_{i=1}^{4} \mu_{i}+\left[\mu_{S}\right.\right. & \left.\left.-\sum_{i=1}^{3} \mu_{i}\left(\beta_{i}^{S}-\beta_{4}^{S}\right)\right] /\left(1-\beta_{4}^{S}\right)\right] \dot{M F P_{4}} \\
& -\sum_{i=1}^{3} \mu_{i} \pi_{i}-\left[\left[\mu_{S}-\sum_{i=1}^{3} \mu_{i}\left(\beta_{i}^{S}-\beta_{4}^{S}\right)\right] /\left(1-\beta_{4}^{S}\right)\right] \pi_{S} .
\end{aligned}
$$

Let $B \equiv \sum_{i=1}^{4} \mu_{i}+\left[\mu_{S}-\sum_{i=1}^{3} \mu_{i}\left(\beta_{i}^{S}-\beta_{4}^{S}\right)\right] /\left(1-\beta_{4}^{S}\right)$ and solve equation 33 for $\dot{M F P}_{4}$ :

$$
\dot{M F P_{4}}=\left(\dot{M F P}+\sum_{i=1}^{3} \mu_{i} \pi_{i}\right) / B+\pi_{S}\left(B-\sum_{i=1}^{4} \mu_{i}\right) / B
$$

With tedious algebra, one can show that $B$ simplifies to be $1 /\left(1-\beta_{4}^{S}\right)$. Using this expression for $B$, equation 34 becomes

$$
\dot{M F P}=\left(1-\beta_{4}^{S}\right)\left(\dot{M F P}+\sum_{i=1}^{3} \mu_{i} \pi_{i}\right)+\left[\beta_{4}^{S}+\left(1-\beta_{4}^{S}\right)\left(1-\sum_{i=1}^{4} \mu_{i}\right)\right] \pi_{S}
$$

This equation, combined with equations 31 and 32, completes the proof for case I. As in case II, the solution is recursive. First, solve for $\dot{M{ }^{\prime}} P_{4}$ from equation 35 . Then, substitute the result into equations 31 and 32 .

\section{Analysis of the Steady State}

The results presented so far do not require the economy to have reached a steady state. We now impose additional conditions to derive the growth-accounting equation for aggregate labor productivity in the steady state.

The first steady-state condition is that labor input must grow at the same rate in every sector:

$$
\dot{L}=\dot{L}_{S}=\dot{L}_{i} \text { for } i=1, \ldots, 4
$$


We also require that all components of a given sector's output grow at the same rate.

Referring back to equations 1 and 2, this condition implies the following for the finaloutput sectors and the semiconductor sector, respectively:

$$
\begin{aligned}
& \dot{Y}_{j}=\dot{C}_{j}=\dot{X}_{j}=\dot{I}_{j, S}=\dot{I}_{j, i} \text { for } i, j=1, \ldots, 4 \\
& \dot{Y}_{S}=\dot{S}_{x}=\dot{S}_{m}=\dot{S}_{i} \text { for } i=1, \ldots, 4
\end{aligned}
$$

In addition, we require that all the growth rates in equations 36-38 are constant and that the imported share of each sector's capital stocks remains constant. Because $I_{j, i}$ grows at a constant rate over time, the stock of this (domestically-produced) capital will grow at the same constant rate. Moreover, with the imported share of each capital stock assumed to be constant, the total stock including imported capital, $K_{j, i}$, will grow at the same rate as the domestically-produced part. This reasoning implies that $\dot{I_{j, i}}=\dot{K_{j, i}}$ and $\dot{I_{j, S}}=\dot{K_{j, S}}$ for all $i$ and $j$. Combining these equalities with equation 37, we obtain

$$
\dot{Y}_{j}=\dot{K}_{j, i}=\dot{K}_{j, S} \text { for } i, j=1, \ldots, 4 \text {. }
$$

\section{Proposition 4}

Under the steady-state conditions in equations $36-39$ and the restrictions on the income shares across sectors (equation 26), the growth-accounting equation for aggregate labor productivity is

$$
\dot{Y}-\dot{H}=\sum_{i=1}^{4}\left(\alpha_{i}^{K} / \alpha^{L}\right)\left(\dot{M F} P_{i}+\beta_{i}^{S} \dot{M F} P_{S}\right)+\dot{q}+\dot{M F P},
$$

where

$$
\dot{M F P}=\sum_{i=1}^{4} \mu_{i} \dot{M F P_{i}}+\mu_{S} \dot{M F P_{S}}
$$




\section{Proof.}

Substitute equations $26,36,38$, and 39 into the growth-accounting equations 10 and 11, and recall that $\gamma^{L}=\alpha^{L}$ and $\gamma_{j}^{K}=\alpha_{j}^{K}$ when we impose the cross-sector restrictions on the income shares. The result is:

$$
\begin{aligned}
& \dot{Y}_{i}=\left(1-\beta_{i}^{S}\right) \alpha^{L} \dot{L}+\sum_{j=1}^{4}\left(1-\beta_{i}^{S}\right) \alpha_{j}^{K} \dot{Y}_{j}+\beta_{i}^{S} \dot{Y}_{S}+\dot{M F P_{i}} \text { for } i=1, \ldots, 4 \\
& \dot{Y}_{S}=\alpha^{L} \dot{L}+\sum_{j=1}^{4} \alpha_{j}^{K} \dot{Y}_{j}+M \dot{F F}_{S} .
\end{aligned}
$$

Equations (40) and (41) form a system of five equations in $\left(\dot{Y}_{1}, \ldots, \dot{Y}_{4}, \dot{Y}_{S}\right)$. Solving this system yields

$$
\begin{aligned}
& \dot{Y}_{i}=\dot{L}+\dot{M F P}_{i}+\sum_{j=1}^{4}\left(\alpha_{i}^{K} / \alpha^{L}\right) \dot{M}_{\dot{F} P_{j}}+\left[\beta_{i}^{S}+\sum_{j=1}^{4}\left(\alpha_{i}^{K} / \alpha^{L}\right) \beta_{j}^{S}\right] \dot{M F P_{S}} \text { for } i=1, \ldots, 4 \\
& \dot{Y}_{S}=\dot{L}+\sum_{j=1}^{4}\left(\alpha_{i}^{K} / \alpha^{L}\right) \dot{M F P_{j}}+\left[1+\sum_{j=1}^{4}\left(\alpha_{i}^{K} / \alpha^{L}\right) \beta_{j}^{S}\right] \dot{M F P_{S}}
\end{aligned}
$$

Now, substitute equations 42 and 43 into equation 3 (the expression for growth in aggregate output) and rearrange terms, noting that $\dot{S}_{x}=\dot{S}_{m}=\dot{Y}_{S}$ from equation 38:

$$
\begin{gathered}
\dot{Y}=\sum_{i=1}^{4} \mu_{i} \dot{Y}_{i}+\mu_{S, x} \dot{S}_{x}-\mu_{S, m} \dot{S}_{m}=\sum_{i=1}^{4} \mu_{i} \dot{Y}_{i}+\left(\mu_{S, x}-\mu_{S, m}\right) \dot{Y}_{S} \\
=\dot{L}+\sum_{i=1}^{4}\left(\alpha_{i}^{K} / \alpha^{L}\right)\left(M \dot{F P}_{i}+\beta_{i}^{S} \dot{M F P_{S}}\right)+\sum_{i=1}^{4} \mu_{i} \dot{M F P_{i}} \\
+\left[\sum_{i=1}^{4} \mu_{i} \beta_{i}^{S}+\mu_{S, x}-\mu_{S, m}\right] M \dot{M F P_{S}} .
\end{gathered}
$$


Recalling that $\dot{L}=\dot{H}+\dot{q}$ and that $\mu_{S}=\sum_{i=1}^{4} \mu_{i} \beta_{i}^{S}+\mu_{S, x}-\mu_{S, m}$ from equation 21, we obtain:

(45) $\dot{Y}-\dot{H}=\sum_{i=1}^{4}\left(\alpha_{i}^{K} / \alpha^{L}\right)\left(\dot{M F P_{i}}+\beta_{i}^{S} \dot{M F P_{S}}\right)+\dot{q}+\sum_{i=1}^{4} \mu_{i} \dot{M F P_{i}}+\mu_{S} \dot{M F P_{S}}$. 


\section{APPENDIX 2: DATA SOURCES}

This appendix describes the data series used in the paper. All data are annual and cover the period from 1973 to 2001 .

\section{Real Output in the Nonfarm Business Sector $(Y)$}

Data through 2000 are from the BLS multifactor productivity dataset. (The version we used was released in March 2002.) In constructing output, BLS relies primarily on the BEA real output series for nonfarm business less housing. Both the BEA and BLS series are superlative indexes of output. For 2001, we extended the BLS series using annual growth rates of BEA's series for real output in nonfarm business less housing (NIPA table 1.8).

Both BLS and BEA have incorporated the effects of technical changes to the CPI back to 1978 (specifically, the introduction of geometric means in the CPI). However, the output data prior to 1978 must be adjusted to be methodologically consistent with the later data. According to the Economic Report of the President (1999, p. 94), the introduction of geometric means prior to 1978 would hold down CPI inflation by 0.2 percentage point per year. From 1973 to 1977, consumption expenditures accounted for about 85 percent of nonfarm business output in current dollars. Thus, the incorporation of geometric means prior to 1978 would reduce inflation in nonfarm business prices by about 0.17 percentage point per year $(=0.2 \times 0.85)$ through 1977 and would boost growth in nonfarm business output by the same amount each year. In 1978, the adjustment is smaller because the growth rate for that year - which depends on the level in 1977 and the level in 1978 - straddles the change in methodology. To account for these effects, we 
added 0.17 percentage point to the growth rate of the BLS series for nonfarm business output for each year through 1977 and about 0.09 percentage point in 1978 .

\section{Price Index for Nonfarm Business Output $(p)$}

We measure $p$ as an implicit price deflator, constructed as the ratio of currentdollar nonfarm business output to real nonfarm business output from the BLS multifactor productivity dataset. For 1974-77, we then adjusted down the rate of change of this series by 0.17 percentage point annually to build in the effects of the CPI revision, as described in the previous paragraph. In 1978, we adjusted down the rate of change in this series by about 0.09 percentage point. For the rate of change in 2001, we extended the BLS series using the annual growth rate of BEA's price index for nonfarm business less housing.

\section{Capital Inputs $\left(K_{C}, K_{S W}, K_{M}, K_{o}\right)$}

We constructed these capital inputs in two steps. The first step develops productive capital stocks for a detailed set of assets. The second step aggregates these detailed stocks to the four capital inputs used in our analysis.

\section{Productive stocks for detailed types of capital}

For each type of capital, we took data through 2000 directly from the BLS multifactor productivity dataset. BLS constructs productive stocks for highly disaggregated asset categories, starting with data on real investment for 61 different types of business capital and then translating these investment flows into productive stocks with the use of hyperbolic age-efficiency profiles. 
We extended these BLS productive stocks to 2001 as follows. ${ }^{\text {目 }}$ For nonresidential fixed capital - which constitutes a large majority of all capital used in nonfarm business we extended the detailed BLS investment series to 2001 using NIPA investment data for five broad asset groups: computers and peripheral equipment, software, communication equipment, other equipment, and nonresidential structures. For each group except computers and peripheral equipment, we used the growth rate of investment in 2001 for the group as a whole to extend the investment series for each asset within the group. ${ }^{\natural}$ For example, we used the 2001 growth rate for overall NIPA software investment to extend the investment series for each of the three different types of software.

For computers and peripheral equipment, we employed a more refined procedure because the trend growth rates can differ substantially across various types of computer hardware. To begin, we used the BLS dataset to calculate the average growth rate of investment in 1999 and 2000 for each type of computer and peripheral equipment mainframes, personal computers, printers, terminals, integrated systems, and three different types of storage devices. These growth rates represented our estimate of "trend" growth in investment for 2001 for each detailed category. Then, we scaled these "trend" rates so that the resulting individual investment series would chain aggregate to the level of total real investment in computers and peripheral equipment in 2001 .

\footnotetext{
${ }^{3}$ BLS actually relies on a two-way disaggregation by type of asset and by industry. For our analysis, we used data by asset that already have been aggregated across industries.

${ }^{4}$ Moylan (2001) highlights methodological revisions that likely will be made to BEA's figures for software investment at the next NIPA benchmark revision in 2003. That discussion raises the possibility that the level of software spending will be revised down.

${ }^{5}$ This scaling procedure does not generate sensible results if the estimated "trend" growth rate of investment for a particular asset differs in sign from the actual 2001 change for the broader group to which it belongs. Because such sign differences periodically occur for some assets within software, communication equipment, other equipment, and nonresidential structures, we used the simpler procedure described above for extending investment in business fixed assets other than computer hardware.
} 
Given an estimate of real investment in 2001 for each type of nonresidential fixed capital, we extended the BLS productive capital stocks to 2001 with the perpetual inventory method. Specifically, for each detailed asset type, we calculated a translation factor $\left(f_{t}\right)$ for each year through 2000 from the following equation:

$$
K_{t}=f_{t} K_{t-1}+\left(I_{t}+I_{t-1}\right) / 2,
$$

where (following BLS methodology) $K_{t}$ is measured as the average of the stocks at the end of years $t$ and $t-1$. We used the value of $f_{t}$ in 2000 and the detailed investment data to construct productive stocks for each type of nonresidential fixed capital for 2001.

The other assets included in BLS' measure of nonfarm business capital are tenantoccupied rental housing, inventories, and land. For tenant-occupied rental housing, we extended the BLS productive stock to 2001 with a simple regression equation. This equation regressed the BLS productive stock on its own lag and on real investment in multifamily residential structures from the NIPAs. The coefficients from this equation, combined with NIPA data on investment in multifamily structures for 2001, generated the estimate of the stock of tenant-occupied rental housing in 2001. For the stock of inventories, we extended the BLS series to 2001 using NIPA inventory data. For the stock of land, we extended the BLS series to 2001 with the average growth rate of this stock for the five years through 2000 .

\section{Aggregation}

BLS uses the Tornquist formula to aggregate the detailed productive capital stocks into measures of capital services. The Tornquist aggregate is a weighted average of the growth rates of the various productive stocks, with the weight for each asset type equal to its estimated share of total capital income. To construct our capital aggregate for 
computer and peripheral equipment $\left(K_{C}\right)$, we applied the Tornquist formula to the eight components of such equipment. For software $\left(K_{S W}\right)$, we followed a similar procedure for the three different types of software. For communication equipment $\left(K_{M}\right)$, the capital services aggregate just equals the productive stock; the Tornquist formula is not needed because we have no asset detail within this aggregate. Finally, to construct $K_{O}$, our first step was to extend the BLS measure of aggregate capital services to 2001 (using the Tornquist formula). Then, we stripped out computer and peripheral equipment, software, and communication equipment from aggregate capital services to arrive at $K_{O}$.

\section{Labor Hours $(H)$}

Through 2000, labor hours are from the BLS multifactor productivity dataset. We extended the data to 2001 using the growth rate in hours of all persons in the nonfarm business sector from the BLS Productivity and Cost release.

\section{Labor Quality ( $q$ )}

BLS measures labor quality as the difference in the growth rate of labor input and labor hours. To calculate labor input, BLS divides the labor force into a number of agesex-education cells, and then constructs a weighted average of growth in hours worked in each cell, with the weight for each cell equal to its share of total labor compensation. Through 2000, our measure of labor quality is from the BLS multifactor productivity dataset. For 2001, we assumed that labor quality generated a contribution of 0.25 percentage point to growth in labor productivity, its average contribution over 19962000. 


\section{Income Shares $\left(\alpha_{j}\right)$}

The income share for each detailed type of nonresidential fixed capital in a given year is calculated from the following equation:

$$
\alpha_{j}=\left[\left(R+\delta_{j}-\Pi_{j}\right) p_{j} K_{j}\right] T_{j} / p Y
$$

We discuss each component of this equation below. Note that these income shares vary from year to year, and are not fixed at a period-average value.

For tenant-occupied rental housing, inventories, and land, the income shares through 2000 were taken directly from the BLS multifactor productivity dataset. For 2001, we extrapolated forward BLS' year-2000 level of capital income for each asset using the trend growth rate from 1995 to 2000. We then divided the estimated 2001 capital income for each asset by total income in nonfarm business to obtain income shares.

Once we estimate the income-share series for each capital asset, the income share for labor equals unity minus the total income share for capital.

\section{Depreciation rate $\left(\delta_{j}\right)$}

For the most part, the depreciation rate for each type of equipment and structure comes from BEA (as presented in Fraumeni (1997), pp. 18-19). However, as indicated above, BEA provides very little information on depreciation rates for the individual types of computers and peripheral equipment; we follow Whelan (2000) and set these depreciation rates equal to a geometric approximation calculated from BEA capital stocks and investment flows. For personal computers, we are uncomfortable with BEA's procedure for depreciation rates, and instead, we set the depreciation rate for PCs equal to 
the 30 percent annual rate for mainframe computers. ${ }^{6}$ For software, we used the BEA depreciation rates described by Herman (2000, p. 19). BEA assumes that prepackaged software has a service life of three years and a depreciation rate of 55 percent per year; own-account and custom software each have service lives of 5 years and a depreciation rate of 33 percent per year.

\section{Expected nominal capital gain/loss $\left(\Pi_{j}\right)$}

We calculated $\Pi_{j}$ as a three-year moving average of the percent change in the price of asset $j\left(p_{j}\right)$. The moving average serves as a proxy for the unobserved expectation of price change. Through 2000, the $p_{j}$ series for each asset is the investment price index from the BLS multifactor productivity dataset. Each $p_{j}$ series is extended to 2001 using the same procedure as that employed for real investment for each asset. Specifically, we extended the detailed BLS price series to 2001 using NIPA investment prices for five broad categories of nonresidential fixed investment: computers and peripheral equipment, software, communication equipment, other equipment, and

\footnotetext{
${ }^{6}$ As described in Herman (2000, p. 18), BEA sets the depreciation rate for personal computers so that 10 percent of the original value remains after five years of service, which implies an annual geometric depreciation rate of 37 percent. By construction, this depreciation rate captures the full loss of value during each year of the assumed five-year service life. In contrast, BEA's depreciation rates for other types of computer hardware are constructed to capture only the loss of value over and above the decline in the asset's constant-quality price index $\left(\Pi_{j}\right)$. This is the appropriate concept of depreciation to combine with $\Pi_{j}$ in order to measure the full loss of asset value in the formula for the income share. However, for personal computers, BEA's depreciation rate, when combined with $\Pi_{j}$, double-counts the loss of value for that asset. One fix for this problem would be to drop the $\Pi_{j}$ term from the income-share formula for PCs. However, this would be appropriate only if BEA's depreciation rate of 37 percent accurately measures the full loss of value. While there is relatively little hard evidence on this subject, our hunch is that PCs typically lose more than 37 percent of their value over the course of a year. Thus, dropping the $\Pi_{j}$ from the user cost formula does not seem an adequate solution to this problem. Instead, we set $\delta_{j}$ for PCs equal to its value for mainframes ( 30 percent per year) and plug this value into the income-share formula, along with the value of $\Pi_{j}$ for PCs. This may not be an ideal approach, but given the very limited research on depreciation for PCs, we judged it to be the best choice at present. (For a fuller discussion of related issues, see Oliner (1994).) Similar problems may affect other assets as well, and we believe that future research in this area is crucial.
} 
nonresidential structures. ${ }^{\square}$ For each individual asset, the resulting rate of price change was applied to the year-2000 level of $p_{j}$ to calculate $p_{j}$ for 2001.

\section{Current-dollar productive capital stock $\left(p_{j} K_{j}\right)$}

For each asset, this series is simply the product of the real productive stock $\left(\mathrm{K}_{\mathrm{j}}\right)$ and the asset price index $\left(\mathrm{p}_{\mathrm{j}}\right)$, both of which are discussed above.

\section{Tax adjustment $\left(T_{j}\right)$}

For each asset, this adjustment equals $(1-c-\tau v) /(1-\tau)$, where $c$ is the rate of investment tax credit, $\tau$ is the corporate tax rate, and $v$ is the present value of $\$ 1$ of tax depreciation allowances. Karl Whelan kindly provided these series, which are discussed further in Whelan (1999).

\section{Current-dollar nonfarm business output $(p Y)$}

Through 2000, this series is from the BLS multifactor productivity dataset. For 2001, we extended the BLS series using the annual growth rate of BEA's series for current-dollar output in the nonfarm business sector less housing.

\section{Nominal net return $(R)$}

We calculated $R$ as the ex post net return earned on the productive stock of nonresidential equipment and structures. Thus, we obtained $R$ as the solution to the following equation for each year in our sample:

$$
\sum_{j=1}^{N}\left[\left(R+\delta_{j}-\Pi_{j}\right) p_{j} K_{j}\right] T_{j} / p Y=\text { BLS series for } \sum_{j=1}^{N} \alpha_{j},
$$

\footnotetext{
${ }^{7}$ Just as for the investment series, the scaling procedure that we use for computer hardware does not generate sensible results if the "trend" rate of price change for a particular asset differs in sign from the actual 2001 change for the broader group to which it belongs. Because these sign differences occur for some non-computer price series, we employed the simpler extrapolation method described above to extend the price series for nonresidential fixed investment other than computer hardware.
} 
where the summations are over all $N$ types of nonresidential equipment, software, and structures. This procedure yielded an annual series for $R$ through 2000 . For 2001, we estimated $R$ from a regression with the following explanatory variables: a constant, two lags of $R$, the rate of price change for nonfarm business output, the acceleration in real nonfarm business output, the unemployment rate, and the share of corporate profits in GNP.

\section{Current-Dollar Output Shares $\left(\mu_{C}, \mu_{S W}, \mu_{M}, \mu_{S}, \mu_{o}\right)$}

The denominator of each output share is current-dollar nonfarm business output $(p Y)$, the data source for which was described above. Here, we focus on the measurement of current-dollar sectoral output, the numerator in each share.

\section{Computer sector}

We use NIPA data on final sales of computers to measure current-dollar computer output $\left(p_{C} Y_{C}\right)$. NIPA final sales equals the sum of current-dollar spending on computers and peripheral equipment in the following categories: private fixed investment, personal consumption expenditures, government expenditures, and net exports of goods and services. This sum omits the small portion of final computer output that ends up in business inventories, as the NIPA inventory data do not break out computing equipment from other inventories.

\section{Software sector}

To estimate $p_{S W} Y_{S W}$, we started with unpublished data from BEA on currentdollar final sales of software from 1987 to 2000 . We then adjusted this series for software not produced in the nonfarm business sector by stripping out BEA's estimate of 
own-account software produced by the government. ${ }^{\text {B }}$ Finally, we extended the 1987 level back to earlier years and the 2000 level forward to 2001 using NIPA data on growth in current-dollar software investment by businesses.

\section{Communication equipment sector}

To estimate $p_{M} Y_{M}$, we used unpublished data from BEA on total current-dollar final sales of communication equipment from 1997 to 2000 . We extended the 1997 level back in time and the 2000 level forward to 2001 using NIPA data on the growth of current-dollar business investment in communication equipment.

\section{Semiconductor sector}

Our series for current-dollar semiconductor output $\left(p_{S} Y_{S}\right)$ equals current-dollar shipments of products in SIC category 36741 (integrated microcircuits). Federal Reserve Board staff construct this shipments series as an input to the Board's index of industrial production, using Census Bureau reports through 1999 and trade data from the Semiconductor Industry Association (SIA) for 2000 and 2001. Because the shipments series is not available before 1977 , we set the value of the semiconductor output share $\left(\mu_{S}\right)$ during 1973-76 equal to its 1977 value.

\section{Other final-output sector}

We estimate current-dollar output in this sector $\left(p_{O} Y_{O}\right)$ as a residual after accounting for all other components of nonfarm business output:

$$
p_{O} Y_{O}=p Y-p_{C} Y_{C}-p_{S W} Y_{S W}-p_{M} Y_{M}-p_{S}\left(S_{x}-S_{m}\right),
$$

\footnotetext{
${ }^{8}$ Estimates of government own-account software from 1996 to 2000 are available as unpublished data from BEA. In addition, Grimm and Parker (2000) provide estimates of government own-account software for 1979 and 1992. Using these values, we linearly interpolated the government own-account series backward in time.
} 
where the final term is current-dollar net exports of semiconductors. (This is the only part of semiconductor production that shows up in domestic final output.) The data sources for $p Y, p_{C} Y_{C}, p_{S W} Y_{S W}$, and $p_{M} Y_{M}$ were described above. We obtained data on current-dollar net exports of semiconductors as follows. For the period from 1989 to 2001, we started with series constructed by Federal Reserve Board staff for current-dollar exports and imports of products in SIC code 3674 (semiconductors and related devices), which are based on detailed figures from the International Trade Commission. Because the 3674 category is broader than just semiconductors, we scaled the export and import series for SIC code 3674 down to 36741 (integrated microcircuits) using the ratio of domestic shipments in 36741 to domestic shipments in 3674 . Prior to 1989 , we did not have detailed trade data, and we extended the export and import series back in time using the rate of change in domestic shipments of semiconductors (the series $p_{S} Y_{S}$ described above).

\section{Ratio of Semiconductor Output to Domestic Semiconductor Use $(1+\theta)$}

Domestic semiconductor use can be expressed as domestic semiconductor output minus net exports of semiconductors. Thus,

$$
1+\theta=Y_{S} /\left[Y_{S}-\left(S_{x}-S_{m}\right)\right]=p_{S} Y_{S} /\left[p_{S} Y_{S}-\left(p_{S} S_{x}-p_{S} S_{m}\right)\right]
$$

where the second equality converts each series to current dollars. The data sources for $p_{S} Y_{S}$ and $p_{S} S_{x}-p_{S} S_{m}$ were described above.

\section{Rates of Relative Price Change $\left(\pi_{C}, \pi_{S W}, \pi_{M}, \pi_{S}\right)$.}

Each $\pi_{i}$ series $(i=C, S W, M$, and $s)$ represents the rate of change in the price ratio 
$p_{i} / p_{O}{ }^{9}$ Here, we describe the data source for each price series that enters these ratios.

\section{Computer sector}

$p_{C}$ is measured as an implicit price deflator for the output of computers in the NIPAs. We calculated this deflator as the ratio of current-dollar computer output (defined as the sum of all final sales of computers and denoted above by $p_{C} Y_{C}$ ) to a chain aggregate of real outlays for the same spending categories, which we denote by $Y_{C}$.

\section{Software sector}

$p_{S W}$ is an implicit price deflator for software produced in the nonfarm business sector. Using NIPA data, we calculated this deflator as the ratio of current-dollar software output (the series $p_{S W} Y_{S W}$ described above) to a chain aggregate of real software outlays denoted by $Y_{S W}$. To construct $Y_{S W}$, we did a "chain strip-out" of government own-account software from total final sales of software, parallel to our calculation of the current-dollar series. The growth rate of the resulting aggregate series for real software outlays was about 1 percentage point per year higher than the growth rate of real business investment in software over 1987-2000, the period over which we can construct $Y_{S W}$. To extend $Y_{S W}$ back to years before 1987 and forward to 2001, we used the annual growth rates of real business investment in software adjusted by this 1987-2000 wedge. 10

\section{Communication equipment sector}

$p_{M}$ is an implicit deflator for the output of communication equipment in the NIPAs. We calculated this deflator as the ratio of current-dollar outlays for

\footnotetext{
${ }^{9} \mathrm{We}$ computed the rate of change in each relative price as the percent change from the prior year's price ratio, not as a log difference. Although growth-accounting studies often use the log difference approximation to calculate rates of change, this approximation is inaccurate for percent changes as large as those observed for the relative prices of computers and semiconductors.

${ }^{10}$ Real software output is the only extrapolated series for which we used a "wedge" adjustment. For other extrapolated series, there was not a significant difference between the growth rate of the series in question and the extrapolator series.
} 
communication equipment (the series $p_{M} Y_{M}$ defined above) to a chain aggregate of real outlays denoted by $Y_{M}$ and constructed in an analogous manner to $p_{M} Y_{M}$. Specifically, to calculate $Y_{M}$ we used unpublished data from BEA on total real final sales of communication equipment from 1997 to 2000. We extended the 1997 level back in time and the 2000 level to 2001 using published NIPA data on the growth of real business investment in communication equipment.

\section{Other final-output sector}

Like the other price series, $p_{O}$ is an implicit deflator, which equals the ratio of current-dollar output for this sector (the series $p_{O} Y_{O}$ defined above) to a chain aggregate of the sector's real output $\left(Y_{O}\right)$. We construct $Y_{O}$ by starting with our series for real nonfarm business output $(Y)$ and then "chain stripping-out" all other components of $Y$ (that is, real output of computers, software, and communication equipment, along with real export and imports of semiconductors). Roughly speaking, the "chain strip-out" inverts equation 3 in appendix 1 to solve for the growth of $Y_{O}$, and the resulting growth rates are then linked together to create a series in index levels. To construct the series for real exports and imports of semiconductors needed for the chain strip-out, we assumed that the price of exports and imports of semiconductors was equal to the semiconductor price series described in the next paragraph.

\section{Semiconductor sector}

For 1977-2001, the data source for $p_{S}$ is the deflator for SIC 36741 that Federal Reserve staff developed to estimate industrial production; we use this series to compute the annual percent change in $p_{S}$ for 1978 through 2001. For years before 1978, we calculate the percent change in $p_{S}$ by extrapolating back in time using data from Grimm 
(1998). Specifically, we calculate the average annual percent change between 1974 and 1977 in Grimm's “Summary price index for MOS memory chips" (p. 12), and then take the ratio of this average 1974-77 percent change to the percent change for 1978 based on the Federal Reserve series. We multiply the 1978 percent change in the Federal Reserve series by this ratio, and use the resulting value as the percent change in $p_{S}$ for each year from 1974 to 1977.

\section{Semiconductors as a Share of Current-dollar Input Costs $\left(\beta_{C}^{S}, \beta_{s W}^{S}, \beta_{M}^{S}, \beta_{o}^{S}\right)$}

\section{Computer sector}

We set $\beta_{C}^{S}$ equal to 0.3 for all years. That is, we assume that semiconductors account for 30 percent of the current-dollar input cost of computer producers. This value lies at the middle of the range employed by Triplett (1996). Although the SIA publishes data on semiconductor usage by the computer industry, these data are not appropriate for our purpose. As noted by Flamm (1997), p. 11, the SIA data cover only the semiconductors sold by "merchant" producers in the open market; these data exclude "captive" production by U.S. computer manufacturers, notably IBM. Thus, the SIAbased measure would greatly understate semiconductor use during the 1970s and 1980s, when IBM was the dominant U.S. computer producer.

\section{Software sector}

We set $\beta_{S W}^{S}$ to zero because semiconductors are not a direct input to software production. (Of course, the software industry uses computers and communication equipment that contain semiconductors, but it does not directly use semiconductors.) 


\section{Communication equipment sector}

We used data from the SIA to construct $\beta_{M}^{S}$. The SIA provides data on worldwide shipments of semiconductors for 1976-2001. The SIA also publishes data from 19851994 on the share of these worldwide shipments purchased by producers of communication equipment in the United States. After 1994, the SIA redefined this latter series to cover "the Americas." We linked the series on the U.S.-only share through 1994 with the series on the Americas share from 1995 forward. (Because the share figures are only available back to 1985 , we set this share for earlier years equal to the 1985 value.) We then multiplied the resulting share series by worldwide semiconductor shipments to calculate the current-dollar value of semiconductors used by the communication equipment industry in the United States. (To the extent that semiconductors are used to produce communication equipment elsewhere in North or South America, the series will overstate semiconductor use in the United States alone from 1995 forward.) To construct $\beta_{M}^{S}$, we divide the series just described by our estimate of the current-dollar value of communication equipment produced in the United States, $p_{M} Y_{M}$. Prior to 1976 (for which data on worldwide semiconductor shipments are not available), we set $\beta_{M}^{S}$ equal to its 1976 value.

\section{Other final-output sector}

To estimate $\beta_{O}^{S}$, recall the expression for $\mu_{S}$ in equation 22 of appendix 1:

$$
\mu_{S}=\sum_{i=1}^{4} \mu_{i} \beta_{i}^{S}(1+\theta)
$$

which can be written with explicit sectoral notation as

$$
\mu_{S}=\left[\mu_{C} \beta_{C}^{S}+\mu_{S W} \beta_{S W}^{S}+\mu_{M} \beta_{M}^{S}+\mu_{O} \beta_{O}^{S}\right](1+\theta) .
$$


Solving this equation for $\beta_{O}^{S}$ yields

$$
\beta_{O}^{S}=\frac{\mu_{S}-(1+\theta)\left[\mu_{C} \beta_{C}^{S}+\mu_{S W} \beta_{S W}^{S}+\mu_{M} \beta_{M}^{S}\right]}{\mu_{O}(1+\theta)} .
$$

The data sources for all series on the right-hand side of this expression have already been discussed. 